\title{
Seasonal variations in the synoptic climatology of air pollution in Birmingham, UK
}

\author{
Edward C. Hodgson ${ }^{1} \cdot$ lan D. Phillips ${ }^{1}$
}

Received: 17 March 2021 / Accepted: 8 September 2021 / Published online: 8 October 2021

(c) The Author(s) 2021

\begin{abstract}
A synoptic typing approach was undertaken to examine the seasonal relationship (winter versus summer) between air mass types and pollutant concentrations of $\mathrm{O}_{3}, \mathrm{PM} 10, \mathrm{NO}_{\mathrm{x}}, \mathrm{NO}_{2}$ and $\mathrm{CO}$ in Birmingham, UK, from 2000 to 2015. Daily means of seven surface meteorological variables were entered into a P-mode principal component analysis. Three principal components explained $72.2 \%$ (72.9\%) of the variance in winter (summer). Cluster analysis was used to group together days with similar PC scores and thus similar meteorological conditions. Six clusters provided the best air mass classification in both seasons. High pollutant concentrations were associated with anticyclonic types. In particular, tropical (polar) continental air mass type was most likely to produce extremely high concentrations in summer (winter). In winter, a sequence of Polar Continental (cool and humid) and Binary Mid-latitude Anticyclonic Maritime-Sub-Polar Cyclonic Maritime (cold and dry) induced severe pollution episodes in all pollutants. Whilst the mean duration of severe pollution episodes varied little between winter and summer $\left(\mathrm{O}_{3}\right.$ was an exception, with severe episodes lasting $20 \%$ longer in summer), high pollutant extremes were more common in winter. This was due to more favourable meteorological conditions (e.g. temperature inversions) and increased anthropogenic emissions during the cold season.
\end{abstract}

\section{Introduction}

The Industrial Revolution brought considerable wealth and development to the coal-powered industrial towns of Britain, including the Black Country to the west of Birmingham and wider West Midlands area. Economic development came at a cost, with emissions of black smoke being up to 50 times higher than present day emissions (Hatton 2017). The considerable epidemiological impacts led to the Clean Air Acts of 1956, 1968, and 1993 being passed to regulate domestic, commercial and industrial emissions (Abbott et al. 2012). Birmingham is Britain's second largest city, with a population of 1.22 million. Multiple industrial sources, a major airport and congested roads result in high pollutant emissions. In particular, combustion from diesel engines accounts for the majority of the city's $\mathrm{NO}_{\mathrm{x}}$ emissions. The Environment Act 1995 produced a national air quality strategy, which gave jurisdiction to local authorities such as Birmingham

Ian D. Phillips

i.d.phillips@bham.ac.uk

1 School of Geography, Earth and Environmental Sciences, University of Birmingham, Edgbaston, Birmingham B15 2TT, UK
City Council to review and tackle their air pollution problem (DEFRA 2018). In 2003, Birmingham was designated as an Air Quality Management Area (AQMA), in which pollutant concentrations must be regularly monitored and policies enacted to reduce levels of harmful pollutants such as $\mathrm{NO}_{2}$ and PM10. Despite this, the concentration of $\mathrm{NO}_{2}$ in Birmingham is up to $50 \%$ higher than recommended levels (DEFRA and DfT 2017). Bloss (2018) reported that poor air quality causes 900 premature deaths in Birmingham every year. In order to satisfy annual and winter pollutant targets, Birmingham City Council has charged $£ 8$ for older private cars to enter the city centre from June 2021 as part of its Clean Air Zone.

Since the 1980s a growing body of research referred to as the 'Delaware Approach' (Kalkstein and Corrigan 1986) has established that the physical and thermodynamic properties of the urban boundary layer play a primary role in influencing the dispersion of pollutants (McGregor and Bamzelis 1995; Shahgedanova et al. 1998). This synoptic typing Delaware Approach adopts an air mass approach to understanding the relationship between weather and pollution. The advantage of such an approach is that it considers the synergistic behaviour of a multitude of atmospheric variables rather than analysing variables such as 
temperature and humidity in isolation (Tselepidaki et al. 1995; McGregor 1999). Crucially, the grouping of multiple surface weather variables in the air mass approach allows one to infer whether conditions are likely to favour pollutant accumulation or suppression. Principal component analysis (PCA) and cluster analysis (CA) are often used to derive the air mass types. PCA identifies groups of highly correlated variables over time. The resulting principal components are linearly independent and explain the maximum amount of variance possible (Yarnal 1993). Many researchers then cluster the PC scores to identify the air mass types. Studies that have used the PCA and CA approach to synoptic typing include McGregor and Bamzelis in Birmingham, UK, (1995) and Shahgedanova et al. (1998) in Moscow. Kalkstein and Corrigan (1986) showed that maritime air masses-characterised by low pressure and high winds-resulted in low $\mathrm{SO}_{2}$ concentrations in Delaware, US due to effective mixing and ventilation. Similarly, maritime cyclonic weather types that are characterised by strong westerly winds were associated with lower pollutant concentrations in Birmingham (McGregor and Bamzelis 1995).

Many studies have acknowledged the tendency of urban air pollutants to persist (Chen et al. 2016). This persistence is a complex phenomenon governed by many inter-related factors. Chelani (2013) showed that CO persistence was dependent on preceding concentrations. Ozone persistence is not dependent on antecedent levels; but is primarily dependent on $\mathrm{NO}_{\mathrm{x}}$ and $\mathrm{CO}$ emissions as precursor sources, and strong sunlight (Varostos et al. 2003). Lonati et al. (2011) found that stable anticyclonic air mass types led to persistently high PM10 concentrations in Milan, Italy. The implications of severe PM10 episodes for daily hospital respiratory admissions in Birmingham were explored by McGregor et al. (1999). Xie et al. (2015) found that a $10 \mu \mathrm{gm}^{-3}$ increase in PM2.5 was associated with a $0.27 \%$ increase in ischaemic heart disease mortality.

The synoptic typing approach considers only the macroscale factors that determine pollutant concentrations. Local factors (e.g. proximity to major roads) can also be significant. This was demonstrated by Liang (2021), who compared a range of pollutants at two sites in Birmingham: a site close to the busy Middle Ring Road in inner Birmingham and a site in the outer suburb of Acock's Green. Mean hourly $\mathrm{NO}_{2}$ concentrations at Acock's Green varied between

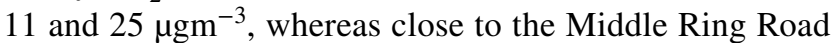
concentrations were much higher (hourly means of 19-40 $\mu \mathrm{gm}^{-3}$ ). Hayer (2021) investigated pollutant concentrations at Birmingham Airport. He sub-set his data to include only those wind directions in which aircraft emissions from the runway were blown towards the air quality monitoring station. Ozone was the only pollutant at the Airport not to meet the British Government's air quality strategy objectives: for instance, there were 14 days in 2016 when the daily maxi-

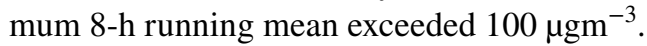

Despite the well-established nature of the weather-pollution relationship, seasonal differences in this association have received comparatively little attention. For instance, McGregor and Bamzelis (1995) derived their air mass types across one calendar year and so did not consider seasonal differences. McGregor et al.'s (1999) application of the air mass type approach to Birmingham considered the winter only. A winter-only study might not be generalisable to other seasons, given the large seasonal variations that exist in weather conditions and pollutant emissions. Domestic energy use increases significantly in colder winter months, with people more likely to use their cars for shorter journeys.

This paper uses a synoptic typing approach to derive air mass types for both winter and summer in Birmingham, so enabling a comparative analysis of the meteorological controls on pollutants between the two seasons to be conducted. The objectives of this paper are as follows:

(i) to derive winter and summer air mass types for Birmingham;

(ii) to assess whether a relationship exists between the air mass types and mean and extreme pollutant concentrations; and

(iii) to examine the seasonal differences in the above relationships

This paper is structured as follows. Section 2 describes the collection and analyses of data. Results are described in Section 3 and then discussed in Section 4. Conclusions are drawn in Section 5.

\section{Data and methodology}

Seven meteorological variables were obtained from the British Atmospheric Data Centre (BADC) for Coleshill $(10 \mathrm{~km}$ east of Birmingham City Centre; altitude $=96 \mathrm{~m})$ : mean sea level pressure (MSLP), air temperature (TEMP), wind speed, wind direction, relative humidity $(\mathrm{RH})$, cloud cover (CLOUD) and rainfall (RAIN). TEMP and RH were measured at $1.25 \mathrm{~m}$ above the ground, and wind speed and direction were recorded $10 \mathrm{~m}$ above the surface. Given that there are no topographic or building obstructions close to the Coleshill site, the site's wind speed and direction are representative of the regional scale airflow. Hourly values of all meteorological variables were abstracted for 15 winters (DJF: 2000-1 to 2014-5) and summers (JJA) from 2000 to 2014 , and used to calculate daily means. The number of days with complete data for all meteorological variables over this period were 1,354 and 1,380 days for winter and summer respectively. Pollutant concentrations will then be related to 
the air mass types derived over this period. The objective of this paper is to compare the two extreme seasons (winter and summer), when the factors that control pollutant concentrations are likely to show the largest difference, and so data for spring and autumn were omitted. Wind direction cannot be entered into the PCA because it is not on a linear scale. To solve this problem, wind speed and direction were used to calculate the zonal $(\mathrm{U})$ and meridional $(\mathrm{V})$ wind components, which were then entered into the PCA.

Daily mean concentrations of $\mathrm{O}_{3}, \mathrm{PM} 10, \mathrm{NO}_{\mathrm{x}}, \mathrm{NO}_{2}$ and $\mathrm{CO}$ were abstracted from DEFRA's air quality archive. Unfortunately, data were not available for one site for the complete 2000-2015 period, so two sites had to be used: Birmingham Centre (2000-4) and Tyburn (2004-15). The Birmingham Centre monitoring station is located in an open pedestrianised area of the City Centre. The nearest building has five storeys and contains offices. The nearest road is $10 \mathrm{~m}$ away and leads to a car park. A busy main road (A456) is located $60 \mathrm{~m}$ to the south of the station. The Tyburn monitoring station is located $4.5 \mathrm{~km}$ north east of the City Centre. The station is positioned on the south side of the busy A38 arterial road outside offices. The Tyburn site is about $700 \mathrm{~m}$ to the north of the M6 motorway. It was decided that Birmingham Tyburn would make up the majority of the dataset given its closer proximity to the meteorological station at Coleshill. The distance between Coleshill and Tyburn $(8 \mathrm{~km})$ is acceptable here because air masses typically cover areas greater than hundreds of square kilometres (Kalkstein and Corrigan 1986). The Tyburn readings are taken next to a busy arterial road and so are significantly higher than readings at Birmingham Centre. In order to produce a homogeneous time series, regression models were used to calibrate the 2000-4 values at Birmingham Centre to those at Tyburn (Table 1). The regression equations were also used to infill any missing values at Tyburn from the other site. Calibration of $\mathrm{CO}$ was not performed because it was only measured at Birmingham Centre until 2008.

The derivation of the air mass types was a two-stage process: principal component analysis (PCA) followed by cluster analysis. Daily means of MSLP, TEMP, U, V, RH, CLOUD and $\log _{10}$ RAIN (dry days were replaced with

Table 1 Regression equations for calibration of Birmingham Centre pollutant data. The $y$ variable is Tyburn Road and the $x$ variable is Birmingham Centre

\begin{tabular}{llll}
\hline Pollutant & Equation & $F$ value & $\begin{array}{l}\text { Signifi- } \\
\text { cance value } \\
(p)\end{array}$ \\
\hline $\mathrm{O}_{3}$ & $y=6.618+0.845 x$ & 5145.313 & $<0.001$ \\
$\mathrm{NO}_{x}$ & $y=10^{(0.478+0.688 \log x)}$ & 1826.226 & $<0.001$ \\
$\mathrm{PM} 10$ & $y=10^{(-0.282+1.17 \log x)}$ & 2074.305 & $<0.001$ \\
$\mathrm{NO}_{2}$ & $y=4.984+0.845 x$ & 1771.937 & $<0.001$ \\
\hline
\end{tabular}

$0.01 \mathrm{~mm}$ before taking the logarithm) were entered into separate P-mode PCAs for winter and summer. PCA is a data reduction technique, which identifies groups of highly correlated variables. The technique allows the majority of the variance in the data set to be explained more efficiently by a smaller number of principal components (PCs). The PCA sheds light on the co-variability of the meteorological variables over time, which in turn is important for understanding temporal variations in pollutant concentrations.

The correlation matrix was used because it standardises the variance of each variable to unity, thus eliminating the problem of different measurement scales. It is desirable for each variable to load strongly on to one PC. This is called simple structure. In the winter PCA, MSLP, TEMP and CLOUD were complex variables; and loaded strongly on to multiple PCs. An orthogonal Varimax rotation was thus applied to the winter PC axes in order to achieve better simple structure. No complex variables were identified for the summer PCA, which meant that rotation was unnecessary. PCs with eigenvalues greater than one were retained because these explain more variance than one original variable (Kaiser 1960).

Cluster analysis was used to group together days with similar PC scores and thus similar meteorological conditions. Again, separate cluster analyses were run for winter and summer using the group average method. Whilst Ward's method is most popular, it priorities equal cluster sizes at the expense of physical air mass interpretation by grouping extreme days with non-extreme days (Kalkstein et al. 1987). By contrast, the group average method focuses on $100 \%$ likeness of adjoining cluster cases by prioritising minimisation of within group variance and maximisation of between group variance (Shahgedanova et al. 1998). The squared Euclidean distance was used as the similarity measure. To determine the number of clusters in both seasons, a dendrogram and scree-plotted agglomeration schedule were used, the latter of which plots the co-efficient of fusion against the number of clusters (Gower and Banfield 1975). These methods allow the researcher to deduce significant betweencluster heterogeneity and thus unique air mass types. These air mass types are primarily defined by temperature (tropical versus polar) and source of air (maritime versus continental). In some cases, the stability and pressure of the air mass were added to the standard air mass definitions where this was thought to be informative.

An independent samples one-way analysis of variance (ANOVA) was conducted for winter and summer to investigate whether pollutant concentrations vary between the air mass types. Logged values of $\mathrm{NO}_{\mathrm{x}}, \mathrm{PM} 10$ and $\mathrm{CO}$ were utilised to satisfy the normality assumption of ANOVA. Whilst ANOVA reveals whether the air masses are different as a whole, it does not show whether one air mass shows a statistically significant difference from the other air masses. Due 
to this limitation, a Tukey test was also performed, in which significant differences in pollutant concentrations between pairs of air masses were identified.

For each pollutant and for both summer and winter datasets separately, a Chi-Square test was used to determine whether the most polluted days (standardised scores $>2$ ) are disproportionately associated with certain air mass types. The null hypothesis $\left(\mathrm{H}_{\mathrm{o}}\right)$ of the test assumes that the number of most polluted days is proportional to the frequency of occurrence of that air mass type. For example, if an air mass occurred on $20 \%$ of days throughout the entire data set, then $\mathrm{H}_{\mathrm{o}}$ assumes that this air mass accounts for $20 \%$ of the most polluted days. The Chi-Square test was also used to ascertain whether three thresholds (high, very high and exceptionally high; see Table 2) for poor air quality were more likely to be exceeded in summer or winter. For each pollutant, the number of days exceeding the WHO's (2005) recommended concentration limit was also noted. This threshold is $50 \mu^{-3} \mathrm{gm}^{-3}$ for $\mathrm{PM} 10$ and $\mathrm{NO}_{2}$, and $100 \mu \mathrm{gm}^{-3}$ for $\mathrm{O}_{3}$. A severe pollution episode was defined for the purposes of this study as a sequence of at least four days with concentrations on all days above the 90th percentile. A percentile approach is often used in the atmospheric sciences to analyse individual and sequences of extreme values in a time series. The dominant air mass type for each episode was noted.

\section{Results}

\subsection{Principal component analysis}

For the winter, three PCs explain $72.2 \%$ of the variance. PC 1 (explained variance $=26.0 \%$ ) has a strong positive association with $\log _{10}$ RAIN and V; and a strong negative relationship with MSLP (Table 3a). PC 1 captures the dominant mode of variability in winter weather conditions, which tend either to be mild and wet with low pressure (high positive PC 1 scores) or cold and dry with high pressure (high negative PC 1 scores). RH and CLOUD have high positive loadings on PC 2 (explained

Table 2 Thresholds for defining exceptionally high, very high and high pollution days for each pollutant. The thresholds are daily means and are defined using standardised $(Z)$ scores

\begin{tabular}{llll}
\hline Pollutant & $\begin{array}{l}\text { Exceptionally } \\
\text { high } \\
\mathrm{Z} \text { score }>3\end{array}$ & $\begin{array}{l}\text { Very high } \\
2<\mathrm{Z} \text { score } \leq 3\end{array}$ & $\begin{array}{l}\text { High } \\
1.75<\mathrm{Z} \text { score } \leq 2\end{array}$ \\
\hline $\mathrm{O}_{3}$ & $\mu \mathrm{gm}^{-3}>90$ & $72<\mu \mathrm{gm}^{-3} \leq 90$ & $68<\mu \mathrm{gm}^{-3} \leq 72$ \\
$\mathrm{NO}_{\mathrm{x}}$ & $\mu \mathrm{gm}^{-3}>110$ & $90<\mu \mathrm{gm}^{-3} \leq 110$ & $90<\mu \mathrm{gm}^{-3} \leq 80$ \\
$\mathrm{PM} 10$ & $\mu \mathrm{gm}^{-3}>51$ & $40<\mu \mathrm{gm}^{-3} \leq 51$ & $38<\mu \mathrm{gm}^{-3} \leq 40$ \\
$\mathrm{CO}$ & $\mu \mathrm{gm}^{-3}>0.7$ & $0.55<\mu \mathrm{gm}^{-3} \leq 0.7$ & $0.45<\mu \mathrm{gm}^{-3} \leq 0.55$ \\
$\mathrm{NO}_{2}$ & $\mu \mathrm{gm}^{-3}>55$ & $45<\mu \mathrm{gm}^{-3} \leq 55$ & $40<\mu \mathrm{gm}^{-3} \leq 45$ \\
\hline
\end{tabular}

Table 3 Principal component loadings for (a) winter and (b) summer

\begin{tabular}{|c|c|c|c|}
\hline & PC 1 & PC 2 & PC 3 \\
\hline \multicolumn{4}{|l|}{ (a) } \\
\hline MSLP & -0.888 & 0.066 & 0.078 \\
\hline TEMP & 0.254 & -0.280 & 0.850 \\
\hline $\mathrm{U}$ & 0.146 & -0.800 & 0.290 \\
\hline V & 0.584 & -0.073 & 0.436 \\
\hline RH & 0.138 & 0.827 & 0.113 \\
\hline CLOUD & -0.010 & 0.534 & 0.672 \\
\hline $\log _{10}$ RAIN & 0.763 & 0.135 & 0.248 \\
\hline \multicolumn{4}{|l|}{ (b) } \\
\hline MSLP & -0.760 & -0.152 & -0.302 \\
\hline TEMP & -0.407 & 0.717 & 0.022 \\
\hline $\mathrm{U}$ & 0.021 & -0.461 & 0.820 \\
\hline $\mathrm{V}$ & 0.342 & 0.685 & 0.452 \\
\hline RH & 0.806 & 0.024 & -0.342 \\
\hline CLOUD & 0.750 & -0.176 & -0.105 \\
\hline $\log _{10}$ RAIN & 0.819 & 0.079 & -0.046 \\
\hline
\end{tabular}

variance $=24.5 \%) ; \mathrm{U}$ is the only variable with a strong negative PC 2 loading, which suggests that increased RH and CLOUD are associated with easterly flows. This is logical because easterly winds are cold in winter, which results in a higher RH and often overcast conditions. By contrast, westerly winds are often accompanied with clearer skies. PC 2 can thus be interpreted as the state of the sky. PC 3 (explained variance $=21.8 \%$ ) is a thermal component. It has a strong positive relationship with TEMP and CLOUD; and a weaker positive relationship with V, U and $\log _{10}$ RAIN. On days with high positive PC 3 scores, temperatures are higher than average, with moderate south-westerlies, extensive cloud cover and drizzle. Days with high negative PC 3 scores are much cooler and clearer.

Three PCs explain $72.9 \%$ of the variance during the summer. PC 1 (explained variance $=39.2 \%$ ) has a strong positive relationship with $\log _{10}$ RAIN, RH and CLOUD; and a strong negative association with MSLP (Table $3 b$ ). On days with high positive PC1 scores, low pressure areas will be present over Britain, bringing cloud and significant rainfall. Days with high negative PC 1 scores are characterised by anticyclonic conditions, with warmer temperatures and blue skies. PC 1 is thus a hygrometric and pressure component. PC 2 (explained variance $=18 \%)$ is capturing the strong covariability between south-easterly airflows from Continental Europe and warmer temperatures. PC 3 (explained variance $=15.7 \%$ ) has a strong positive association with $\mathrm{U}$, and a moderate inverse association with RH and MSLP. Days with high positive PC 3 scores have strong westerly winds and moderately low pressure, in which depressions driven by strong Atlantic westerlies travel eastwards over Britain. 


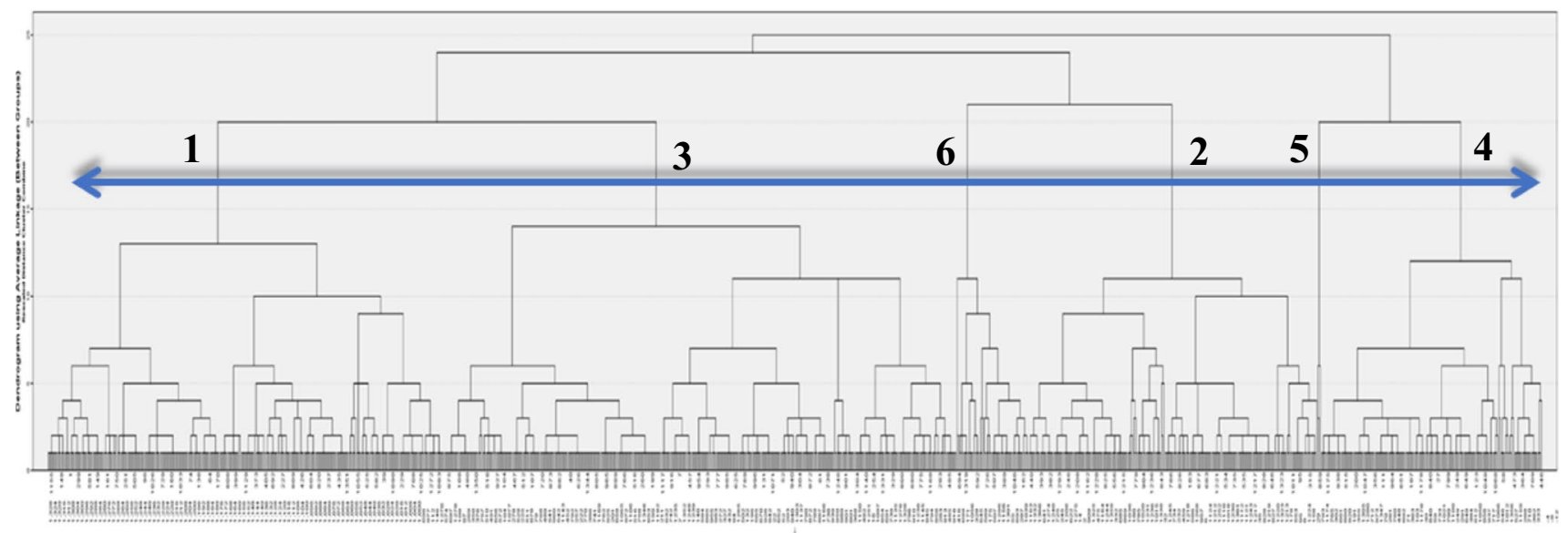

Fig. 1 Dendrogram for the winter cluster analysis. The distance between merged clusters is shown on the $y$ axis. The horizontal line is labelled with the six clusters as described in the text. Clusters one and

On days with high negative PC 3 scores, the wind tends to blow from the east and MSLP is higher. PC 3 is thus a zonal wind component.

\subsection{Winter air mass types}

For the winter, the dendrogram (Fig. 1) and agglomeration schedule indicate that the retention of six clusters is most appropriate. The properties of each air mass type are now described by identifying the common features of the surface synoptic charts on a large number of days in each cluster (Fig. 2 and Table 4).

Type 1: Anticyclonic tropical maritime

With south-westerly winds, conditions are relatively mild with high cloud cover.

Above average pressure suppresses the amount of rainfall. Typically associated with the passage of warm fronts, although cold and occluded fronts can on occasions bring heavier rainfall to the English Midlands. High pressure is positioned over France and Iberia, with depressions moving eastwards between Scotland and Iceland.

Type 2: Unstable tropical maritime

The wettest cluster with the lowest pressure. Birmingham is affected by deep Atlantic lows, cold fronts and strong south-westerly winds.

Type 3: Polar continental

Much cooler than the first two air mass types, and so has a higher relative humidity. The wind direction is variable, but always from a cold, continental source. Pressure is usually high; rainfall is moderate, with occasional heavy downpours. Nocturnal radiative cooling brings morning fog, which dissipates by early afternoon. four are the most dissimilar because they are positioned furthest apart on the dendrogram

Type 4: Binary mid-latitude anticyclonic maritime-subpolar cyclonic maritime (AM-SCM) (McGregor 1999) Northerly winds drive very cold conditions, with low cloud cover and so largely clear skies. Typically features a well-developed mid-Atlantic anticyclone, with a depression of moderate intensity lying between Iceland and Scandinavia. Rainfall decreases as the mid-Atlantic high moves towards Britain.

Type 5: Extreme arctic maritime

Occurs on only 3 days. Characterised by north-westerly winds, which bring bitterly cold temperatures.

Type 6: Returning polar maritime

This air mass is characterised by fairly mild temperatures, pressure close to the long-term average, strong westerly winds, and moderate cloud cover and rainfall. Depressions track eastwards between Iceland and Norway. When the isobars are traced back into the western Atlantic, they originate from the Greenland and Canada region.

\subsection{Summer air mass types}

The clustering co-efficients accelerate markedly six stages from the end of the agglomeration schedule. The evidence from the agglomeration schedule and the dendrogram (Fig. 3) suggests that six clusters again provide the best air mass classification (Fig. 4 and Table 5). Specifying fewer clusters would have resulted in days with dissimilar weather conditions being grouped together into one cluster.

Type 1: Tropical maritime

Predominantly wet and cloudy, with moderate temperatures and strong south-westerlies. This air mass typically originates from the Azores and contains active frontal systems. Rainfall was as high as $33.6 \mathrm{~mm}$ on one day. 
Fig. 2 Case studies of the six winter air mass types (Source: Willand Weather, UK Met Office MSLP Charts)
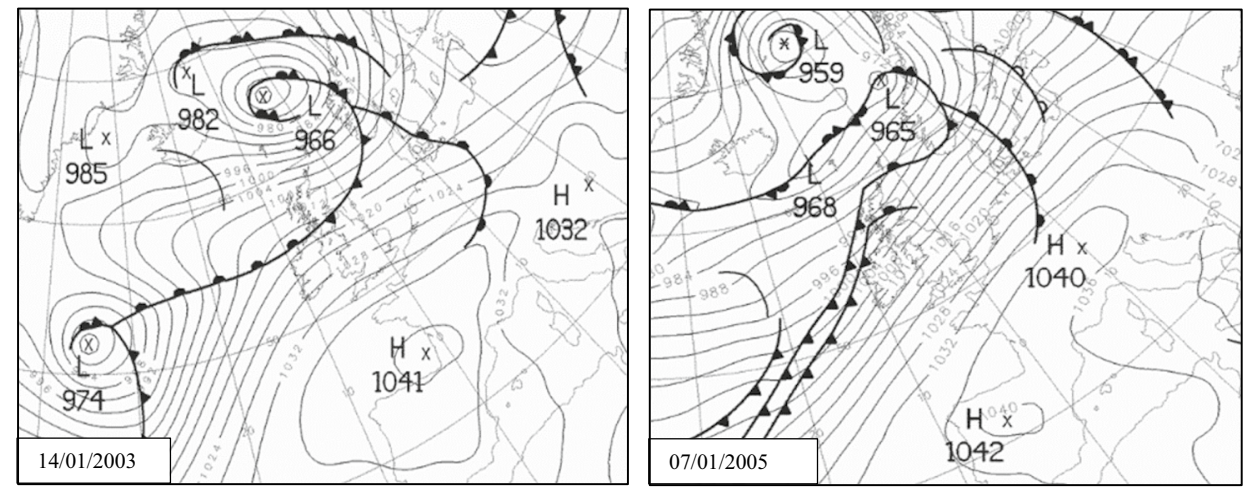

TYPE 1 ANTICYCLONIC TROPICAL MARITIME
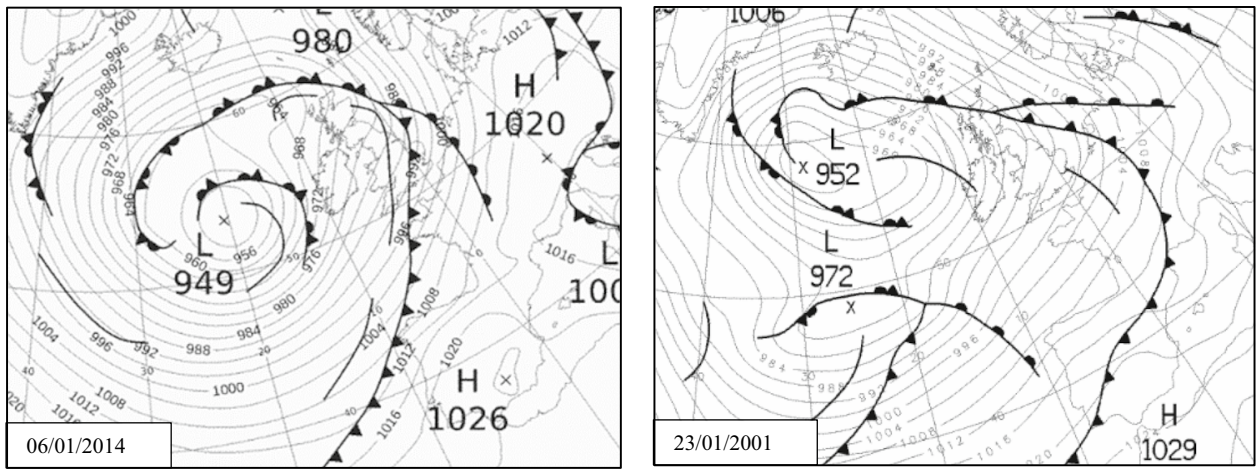

TYPE 2 UNSTABLE TROPICAL MARITIME
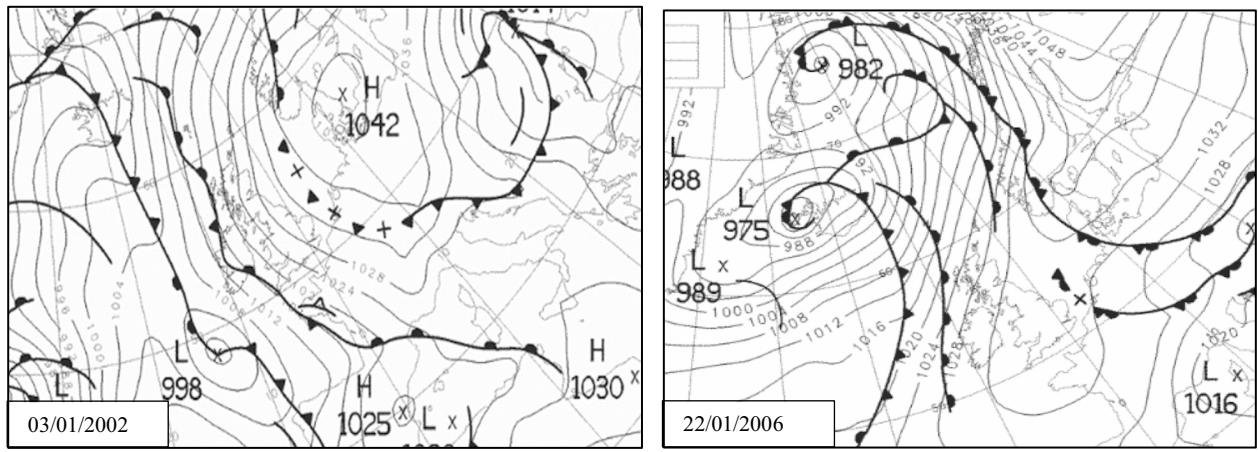

TYPE 3 POLAR CONTINENTAL

Type 2: Transitional polar arctic

Low pressure centred over southern England or northern France leads to cold north-easterly winds transporting Scandinavian or Arctic air to Birmingham. This is by far the wettest air mass type. Anticyclones in the mid-Atlantic and Eastern Europe are common in this situation.

Type 3: Stable anticyclonic tropical

Characterised by moderate westerlies, temperatures and cloud cover. Whilst the air has a long sea track, high pressure over southern Britain is the dominant feature and results in mainly dry conditions.

Type 4: Mild stable polar continental
High pressure and north-easterly winds usually bring low rainfall. Significant low-level cloud cover brings morning fog, with potential for heavy rain when there are disturbances embedded in the flow and a longer North Sea fetch.

Type 5: Tropical continental

The driest and warmest air mass type, with low cloud cover and a gentle south-easterly breeze. High pressure centred in the southern North Sea leads to settled conditions.

Type 6: Polar maritime 
Fig. 2 (continued)
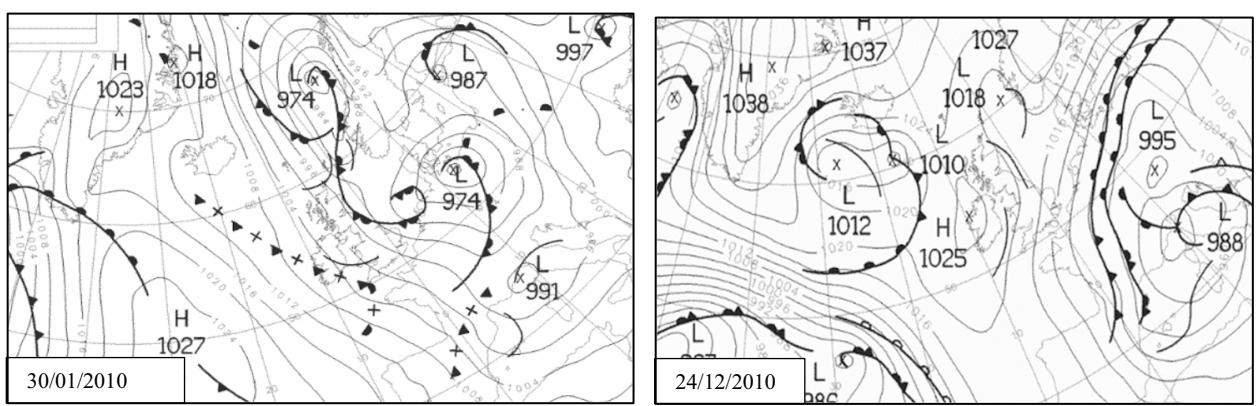

\section{TYPE 4 BINARY MID-LATITUDE ANTICYCLONIC MARITIME - SUB-POLAR CYCLONIC MARITIME}
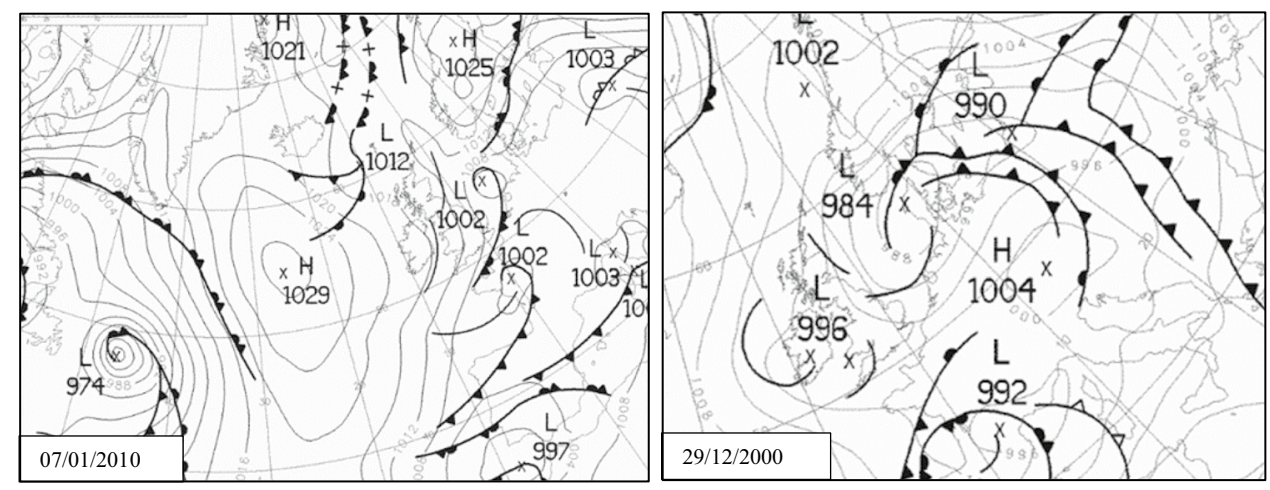

TYPE 5 EXTREME ARCTIC MARITIME
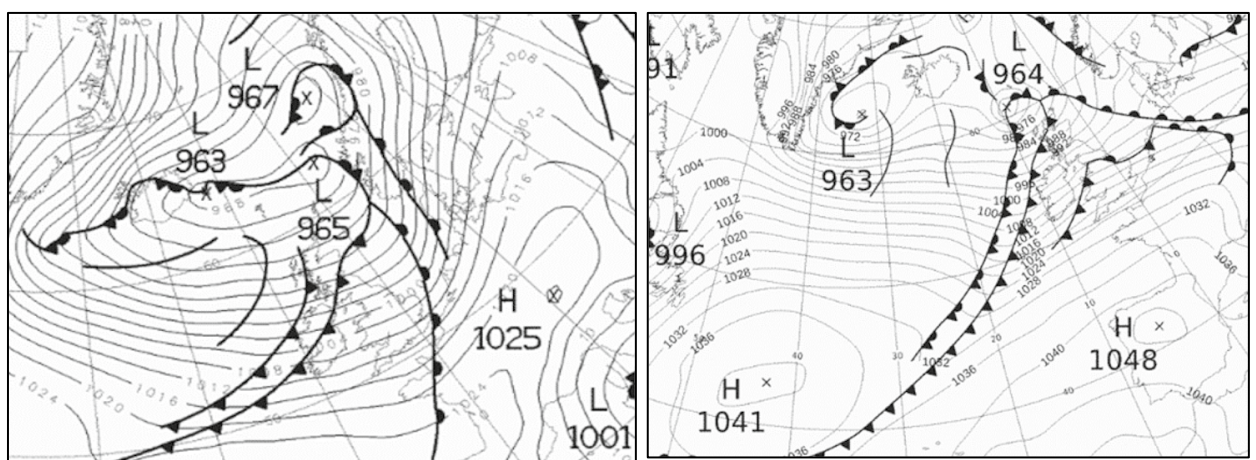

TYPE 6 RETURNING POLAR MARITIME

Table 4 Arithmetic means of the meteorological variables for the six winter air mass types for Coleshill from 2000-1 to 2014-5

\begin{tabular}{lllllllll}
\hline $\begin{array}{l}\text { Air mass } \\
\text { type }\end{array}$ & Number of days & TEMP $\left({ }^{\circ} \mathrm{C}\right)$ & MSLP (hPa) & U (Knots) & V (Knots) & RH (\%) & $\begin{array}{l}\text { CLOUD } \\
\text { (Oktas) }\end{array}$ & $\begin{array}{c}\text { RAIN (mm) } \\
1\end{array}$ \\
\hline 353 & 7.8 & 1018.5 & 4.3 & 4.6 & 86.6 & 6.5 & 1.52 \\
2 & 257 & 5.4 & 997.3 & 3.8 & 6.3 & 86.0 & 4.9 & 3.74 \\
3 & 456 & 3.0 & 1016.9 & 1.5 & 0.5 & 92.3 & 6.8 & 1.90 \\
4 & 197 & 0.7 & 1021.1 & 0.8 & -2.2 & 82.9 & 2.9 & 0.03 \\
5 & 3 & -6.5 & 1003.4 & 1.8 & -2.3 & 87.7 & 1.5 & 0.01 \\
6 & 64 & 7.0 & 1011.1 & 10.1 & 2.3 & 74.4 & 4.4 & 1.43 \\
\hline
\end{tabular}




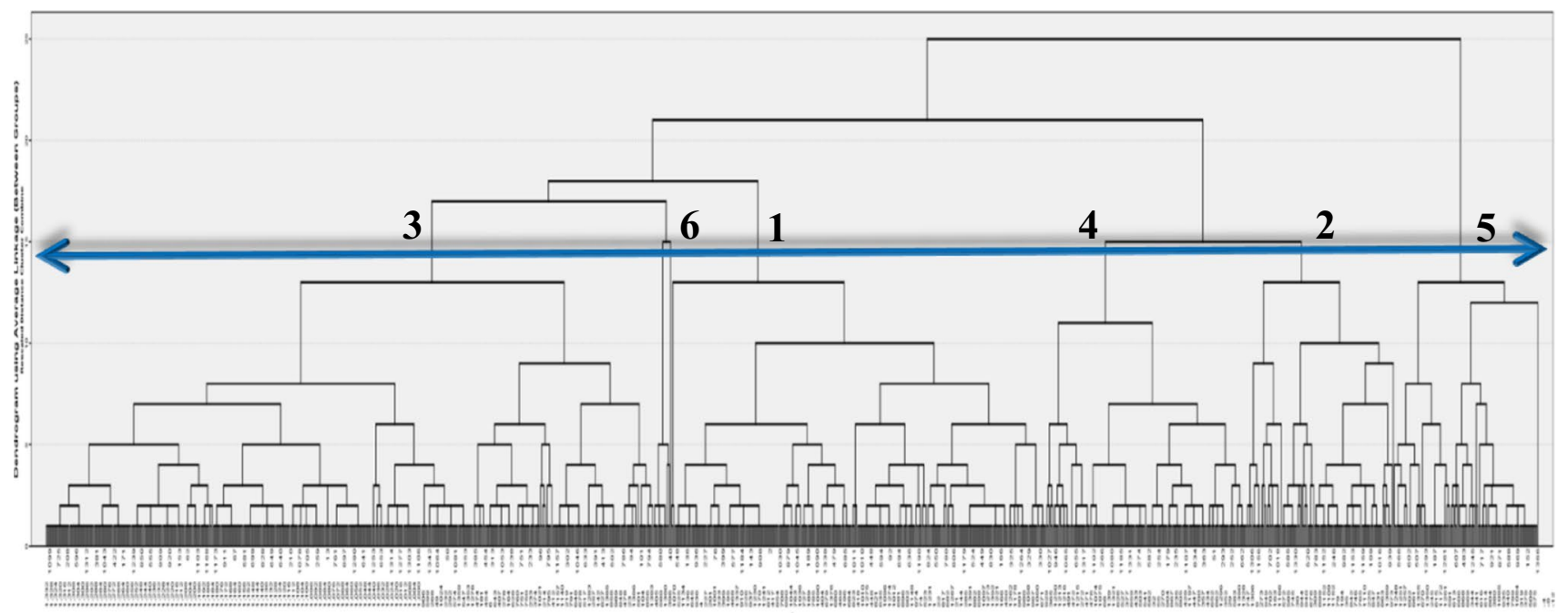

Fig. 3 Dendrogram for the summer cluster analysis. The distance between merged clusters is shown on the $y$ axis. The horizontal line is labelled with the six clusters as described in the text. Clusters three

This cluster contains only 16 days. Temperatures are on the cool side, with light to moderate rainfall. A low is typically situated over north-west Scotland, which brings strong westerlies to Britain.

\subsection{Pollutant variability with air mass type}

All five pollutants show statistically significant differences between the six air mass types at the $99.9 \%$ confidence level in both winter and summer (Table 6). As Snedecor's variance ratio $F$ is considerably greater than one, there is far more variance in pollutant concentrations between the air mass types than within types. For all five pollutants, the $F$ ratio is larger in the winter. This means that concentrations vary more with air mass type in winter than in summer. When all air mass types are considered together, pollutant concentrations are far more variable in winter than in summer. This is especially the case for $\mathrm{NO}_{\mathrm{x}}$ (winter standard deviation $=66.5 \mathrm{\mu gm}^{-3}$, summer standard deviation $=15.6$ $\mu \mathrm{gm}^{-3}$ ). Nearly all of the standard deviations for the individual winter air mass types are higher than their closest summer counterparts.

Difference matrices are used to represent the results of the post hoc Tukey tests. In these matrices, a matrix cell entry denotes a statistically significant difference in the concentration of the given pollutant at the $99 \%$ confidence level.

In the winter (Fig. 5), $\mathrm{NO}_{2}$ and $\mathrm{O}_{3}$ have the largest number of statistically significant differences between pairs of air mass types (12 and 10 respectively). PM10 has the lowest number (six) of significant differences between air masses. This means that PM10 does not show a significant difference between nine pairs of air masses. Across all pollutants, and five are the most dissimilar because they are positioned furthest apart on the dendrogram

returning Polar Maritime (air mass type six) is responsible for the largest number of significant differences between pairs of air masses (20), with Extreme Arctic Maritime (type five) having the least pairings (eight).

During the summer (Fig. 6), PM10 and CO have the largest and smallest number of statistically significant differences between pairs of air mass types at 11 and six respectively. The Transitional Polar Arctic (type two), Stable Dry Anticyclonic Tropical (type three) and Tropical Continental (type five) all have the largest number of significant differences (16). This means that these three air masses are the most distinctive in terms of concentrations. In particular, air mass type three shows statistically significant differences at the $99 \%$ confidence level with types two and four across all five pollutants.

\subsection{Distribution of air mass types on the most polluted days}

Winter air mass type five was excluded from the Chi-Square test because it occurred on only three days and so violated the $20 \%$ rule for expected counts. The test results show that the most polluted days in winter $(Z$ score $>2)$ show a significant association with the air mass type at the $99.9 \%$ confidence level (Table 7a and Fig. 7). In winter, air mass type six is not present for any pollutant except $\mathrm{O}_{3}$. All pollutants show a statistically significant relationship with summer air mass type at the 0.01 level or better (Table $7 b$ ). In particular, high $\mathrm{NO}_{\mathrm{x}}, \mathrm{PM} 10$ and $\mathrm{CO}$ concentrations occur disproportionately under summer air mass type three, accounting for $49 \%, 51 \%$ and $65 \%$ of high concentration days respectively (Fig. 8). 
Fig. 4 Case studies of the six summer air mass types (Source: Willand Weather, UK Met Office MSLP Charts)

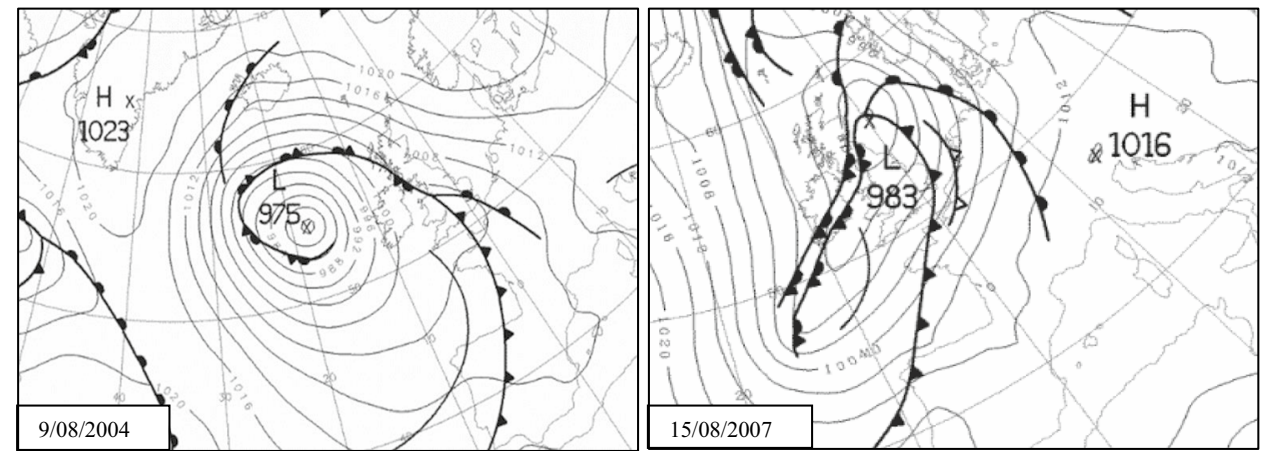

TYPE 1 TROPICAL MARITIME

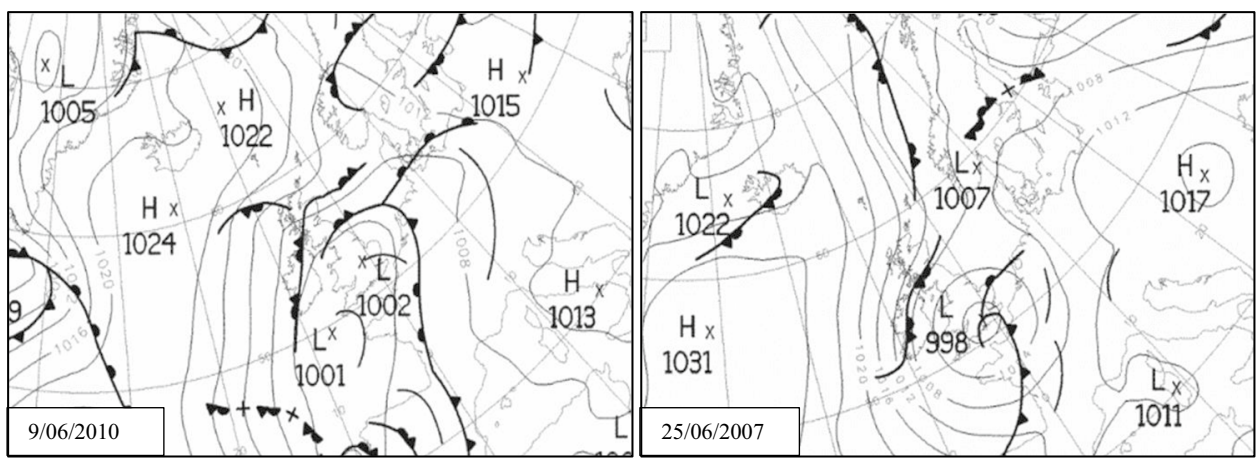

TYPE 2 TRANSITIONAL POLAR ARCTIC

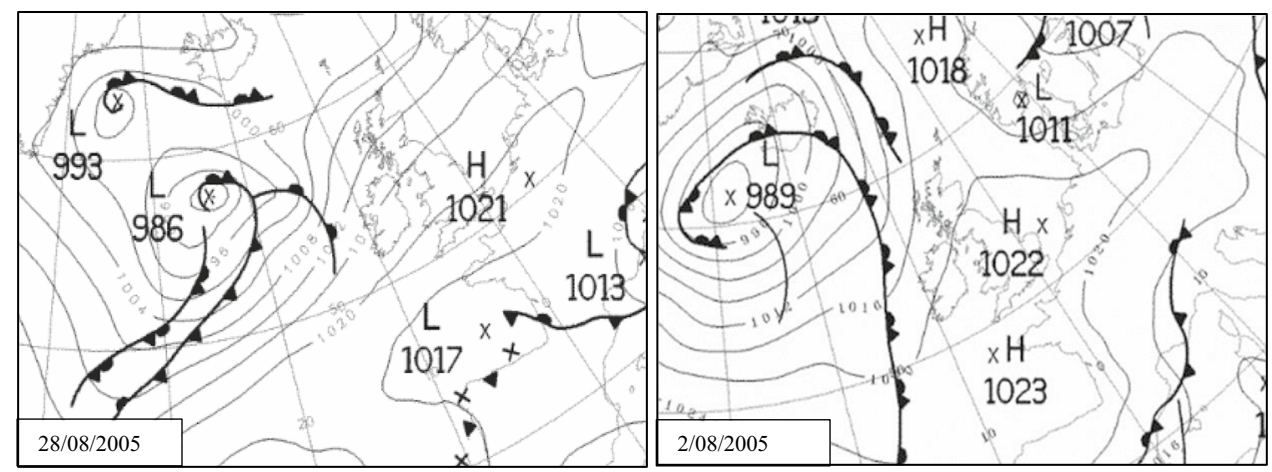

TYPE 3 STABLE ANTICYCLONIC TROPICAL

\subsection{Severe pollution episodes}

A severe pollution episode was defined as a sequence of at least four days with concentrations above the 90th percentile. Figure 9 clearly shows that Polar Continental air mass type (AT) 3 and AM-SCM AT 4 are the most dominant air masses in severe pollution episodes in winter. Extreme Arctic Maritime (AT 5) and Returning Polar Maritime (AT 6) do not appear at all. Anticyclonic Tropical Maritime (AT 1) and AM-SCM (AT 4) often persist for the majority of the severe pollution episodes in which they dominate.

In summer, Tropical Continental AT 5 and Mild Stable Polar Continental AT 4 are the air masses most conducive to severe pollution episodes (Fig. 10). Polar Maritime AT 6 does not appear at all, with Transitional Polar Arctic AT 2 also making minimal impact. Tropical Continental (AT 5) and Stable Anticyclonic Tropical (AT 3) tend to persist for the majority of the severe pollution episode in which they dominate.

\subsection{Cross-seasonal comparison of pollution episode severity}

Figure 11 reveals that whilst the difference in length in days of pollution episodes varies only minimally between summer and winter for each pollutant, average 
Fig. 4 (continued)

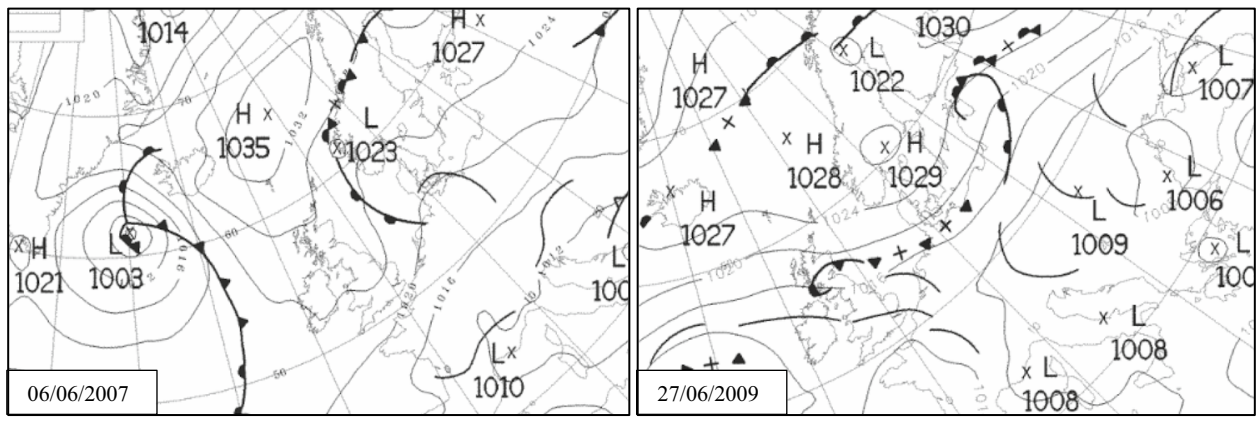

TYPE 4 MILD STABLE POLAR CONTINENTAL
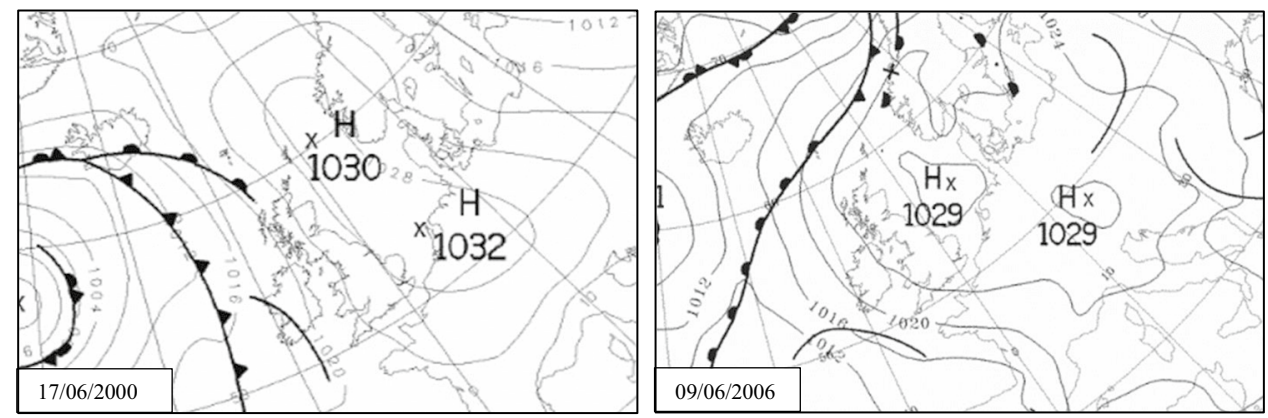

TYPE 5 TROPICAL CONTINENTAL
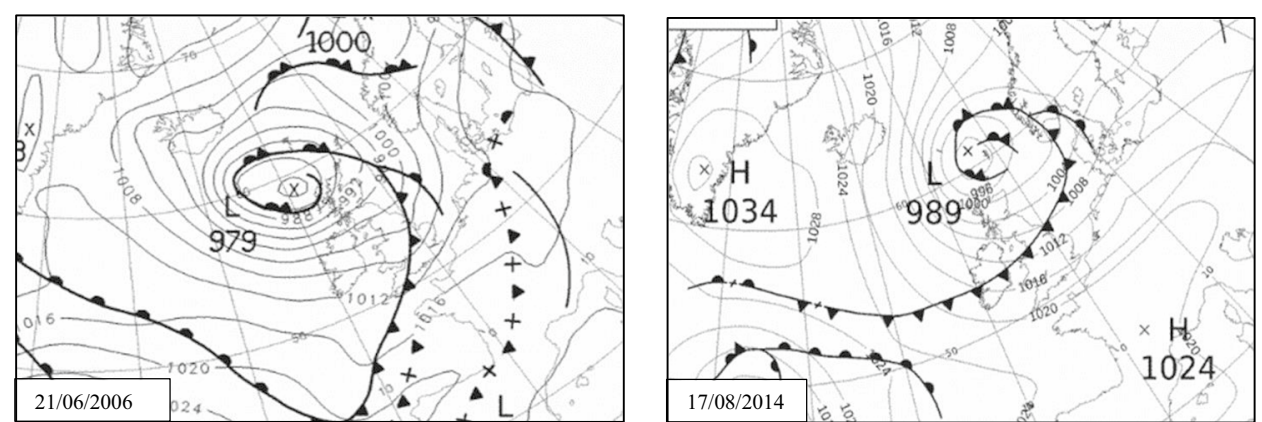

TYPE 6 POLAR MARITIME

Table 5 Arithmetic means of the meteorological variables for the six summer air mass types for Coleshill from 2000 to 2014

\begin{tabular}{lllllllll}
\hline $\begin{array}{l}\text { Air mass } \\
\text { type }\end{array}$ & Number of days & TEMP $\left({ }^{\circ} \mathrm{C}\right)$ & MSLP (hPa) & U (Knots) & V (Knots) & RH (\%) & $\begin{array}{l}\text { CLOUD } \\
\text { (Oktas) }\end{array}$ & $\begin{array}{c}\text { RAIN (mm) } \\
1\end{array}$ \\
\hline 335 & 15.8 & 1008.4 & 2.1 & 5.4 & 82.8 & 6.2 & 3.9 \\
2 & 131 & 13.5 & 1010.2 & 1.0 & 1.9 & 89.8 & 7.2 & 8.2 \\
3 & 542 & 15.6 & 1017.3 & 3.4 & 0.1 & 73.4 & 4.7 & 0.4 \\
4 & 179 & 15.8 & 1019.4 & 1.1 & 1.7 & 78.9 & 5.5 & 0.9 \\
5 & 129 & 20.2 & 1018.7 & 1.3 & 2.2 & 70.1 & 3.1 & 0.2 \\
6 & 16 & 14.0 & 1007.4 & 8.2 & 1.1 & 72.4 & 5.6 & 1.0 \\
\hline
\end{tabular}

concentrations for all pollutants are higher in the winter. The exception is $\mathrm{O}_{3}$, which has greater concentrations and longer episode duration in summer. This is to be expected given that increased summer sunshine hours are conducive to increased photolysis. $\mathrm{NO}_{\mathrm{x}}$ has much higher concentrations in winter than summer, whilst PM10, $\mathrm{CO}$ and $\mathrm{NO}_{2}$ are only slightly higher. 
Table 6 Results of the one-way analysis of variance of pollutant concentrations versus air mass type. All $F$ ratios are statistically significant at the 0.001 level

\begin{tabular}{lrl}
\hline Pollutant & Winter $F$ & Summer $F$ \\
\hline $\mathrm{O}_{3}$ & 145.978 & 57.468 \\
$\mathrm{PM} 10$ & 82.683 & 57.035 \\
$\mathrm{NO}_{x}$ & 81.367 & 21.096 \\
$\mathrm{NO}_{2}$ & 75.054 & 27.706 \\
$\mathrm{CO}$ & 52.385 & 12.692 \\
\hline
\end{tabular}

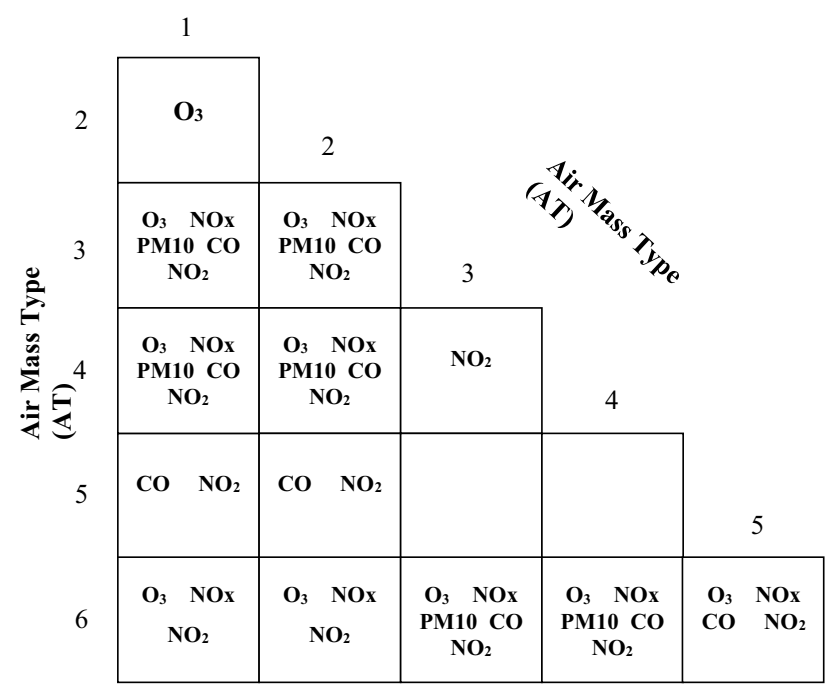

Fig. 5 Air mass type pollution difference matrix for the winter. Pollutants that appear in the matrix show a statistically significant difference at the $99 \%$ confidence level between the pair of air mass types shown

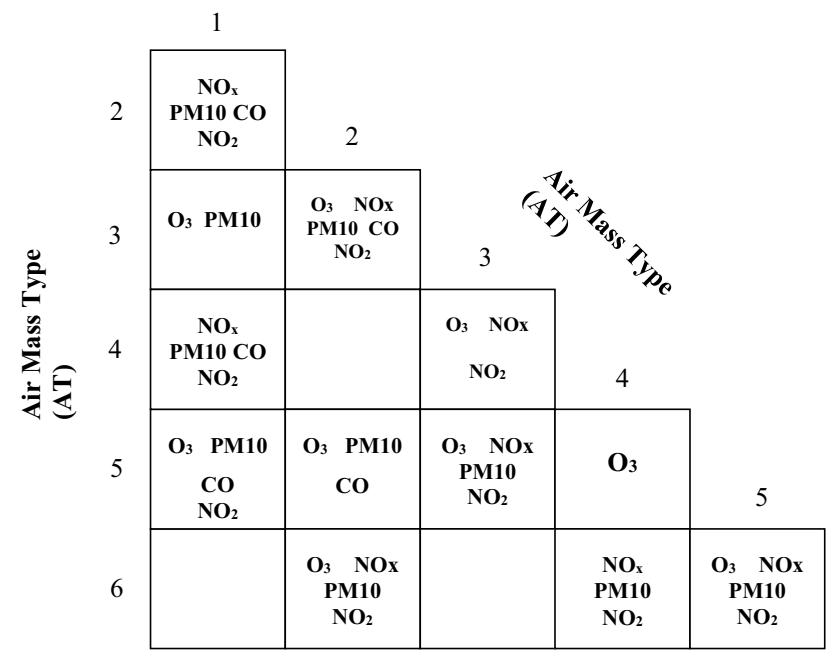

Fig. 6 Air mass type pollution difference matrix for the summer. Pollutants that appear in the matrix show a statistically significant difference at the $99 \%$ confidence level between the pair of air mass types shown
Table 7 Results of the ChiSquare tests for (a) winter and (b) summer. In the winter, all associations are statistically significant at the 0.001 level $(\mathrm{df}=4)$. Winter AT5 was removed from the Chi-Square test because it only occurred on only 3 days $(0.2 \%)$ and so violated the $20 \%$ rule for expected counts. There are five degrees of freedom in the summer because all six air mass types were used

\subsection{Cross-seasonal comparison of pollution extreme values}

The thresholds for high, very high and exceptionally high concentrations are defined in Table 2. The Chi-Square test is applied to determine whether these thresholds are more likely to be exceeded in winter or summer. Apart from $\mathrm{O}_{3}(p=0.024)$, the pollutants all show a statistically significant difference in their frequency of occurrence between winter and summer at the $99.9 \%$ confidence level. These high pollutant thresholds are far more likely to be exceeded in winter than in summer, with the exception of $\mathrm{O}_{3}$. The study period is 15 winters (December 2000 to February 2015) and 15 summers (2000 to 2014). During this study period, there were 317 days in winter when $\mathrm{NO}_{2}$ exceeded the WHO's (2005) recommendation

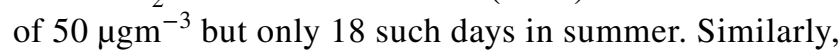
PM10 exceeded the WHO's $50 \mu \mathrm{gm}^{-3}$ threshold on 37 winter days but only on six summer days (Fig. 12).

\section{Discussion}

\subsection{Principal component analysis}

In winter, days with high positive PC 1 scores (explained variance $=26.0 \%$ ) are characterised by unstable, precipitation-bearing Atlantic air mass passage over Britain. The winter-only assessment of synoptic airmass types in the same location by McGregor et al. (1999) shared this atmospheric pattern, although it accounted for only $12.5 \%$ of the variability as their PC 3. PC 2 is a hygrometric zonal wind component, in which strong positive days induce cloudy, foggy conditions with cold easterly winds. Kalkstein and Corrigan's (1986) identified these conditions, in which north-easterly winds brought low-level mist and thus poor 

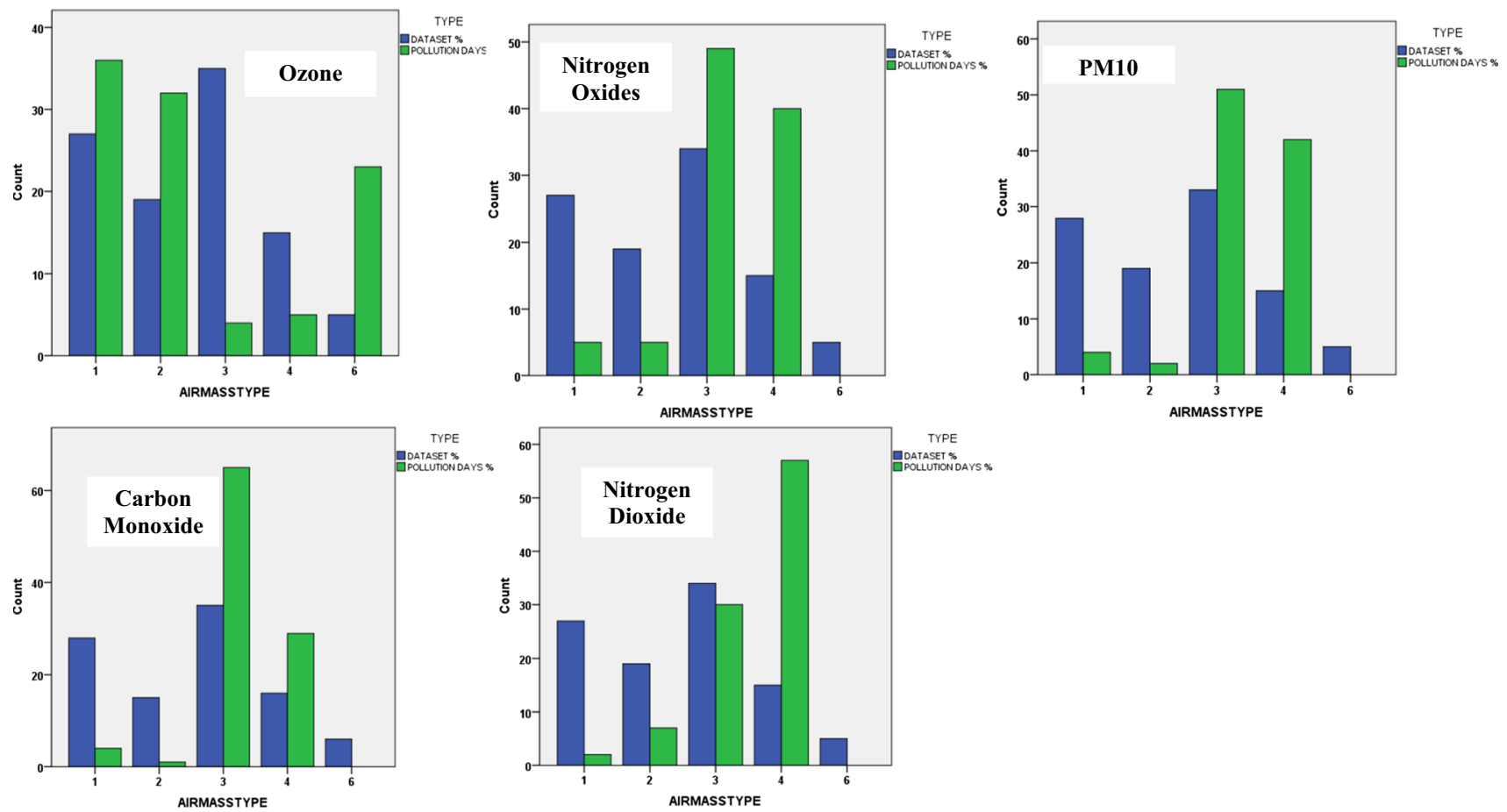

Fig. 7 Comparison between the percentage occurrence of the air mass types across the whole winter and the percentage occurrence of days with high pollutant concentrations
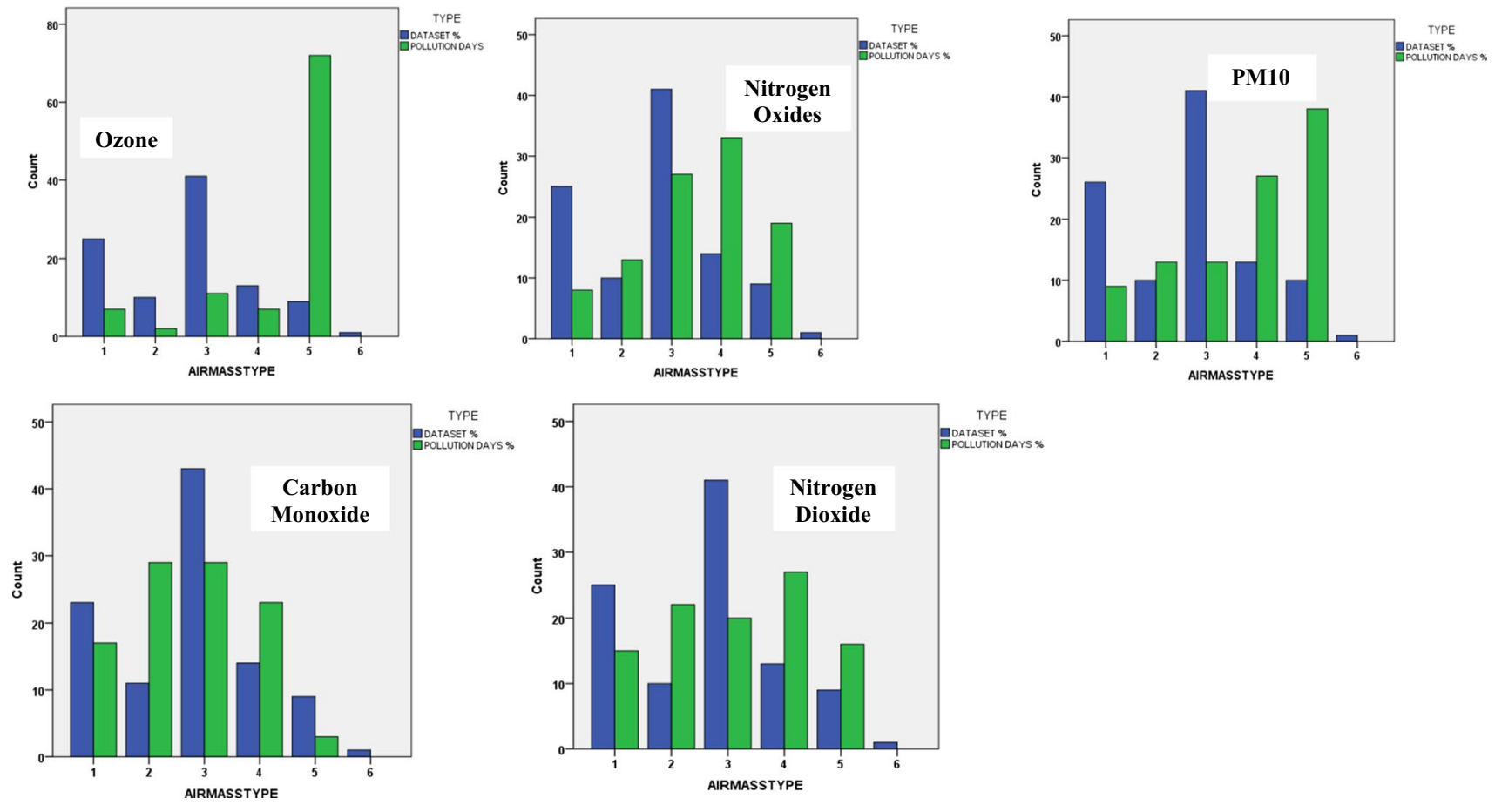

Fig. 8 Comparison between the percentage occurrence of the air mass types across the whole summer and the percentage occurrence of days with high pollutant concentrations 


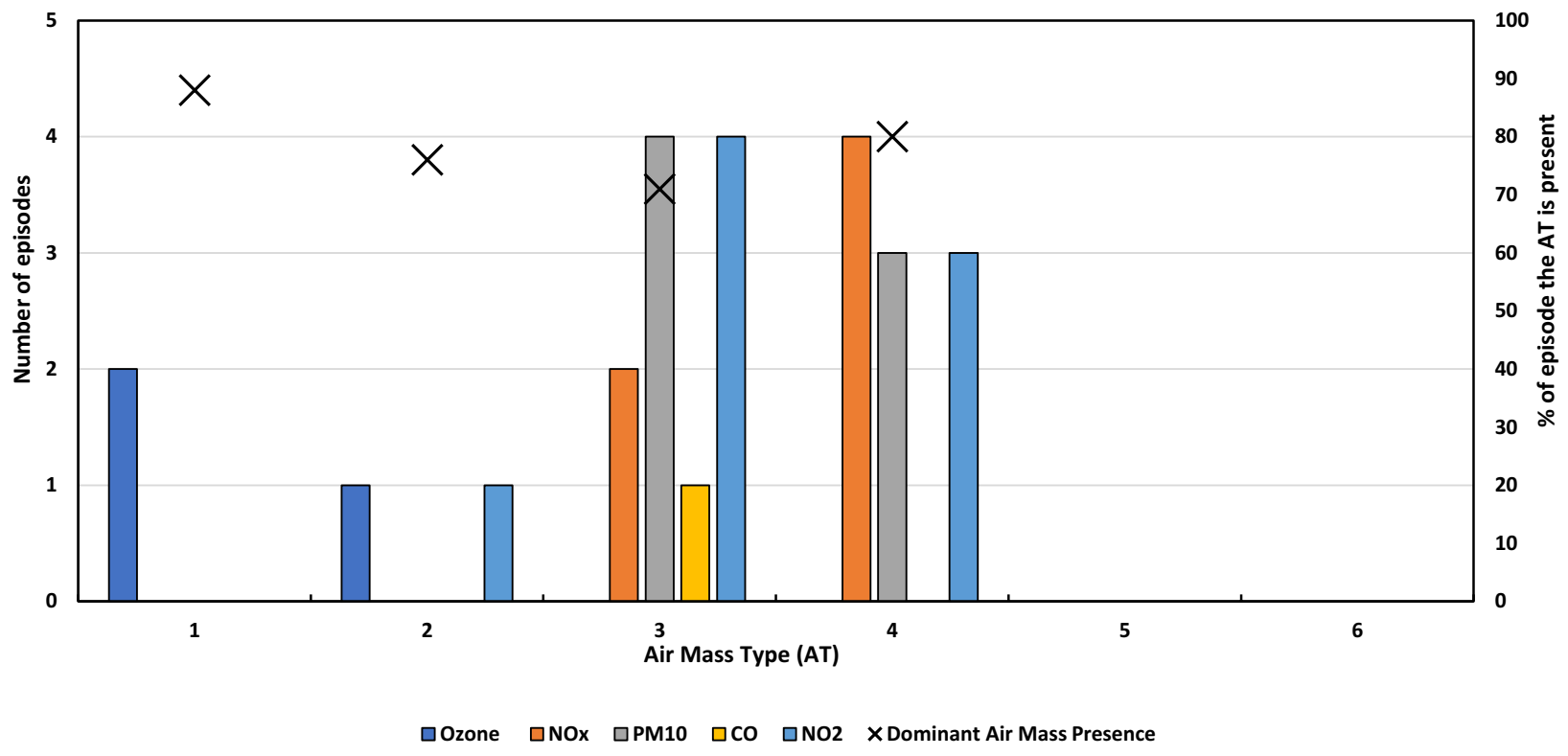

Fig. 9 Number of severe winter pollution episodes per air mass and the relative dominance of that air mass in the episodes. The block cross represents the percentage of the pollution episode's duration in which the dominant air mass type (AT) is present

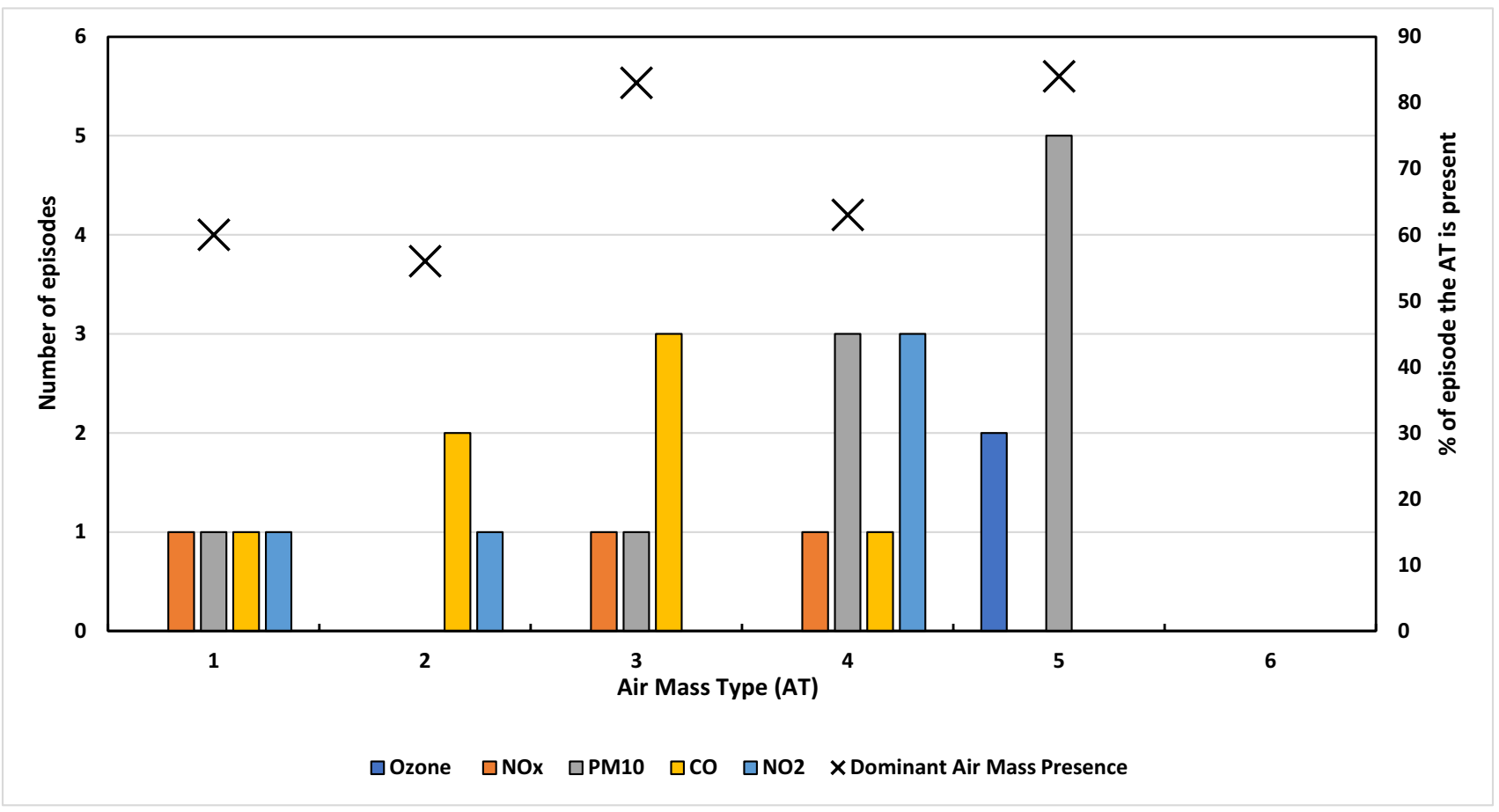

Fig. 10 Number of severe summer pollution episodes per air mass and the relative dominance of that air mass in the episodes. The block cross represents the percentage of the pollution episode's duration in which the dominant air mass type (AT) is present

visibility to Delaware, US. PC $3(21.8 \%)$ is a thermal component; conditions are anomalously mild on days with high positive scores. This pattern was also found in Birmingham by McGregor and Bamzelis (1995) and McGregor et al. (1999), but appeared as their PC 1 rather than PC 3. The statistically significant PCs collectively reveal that in winter 


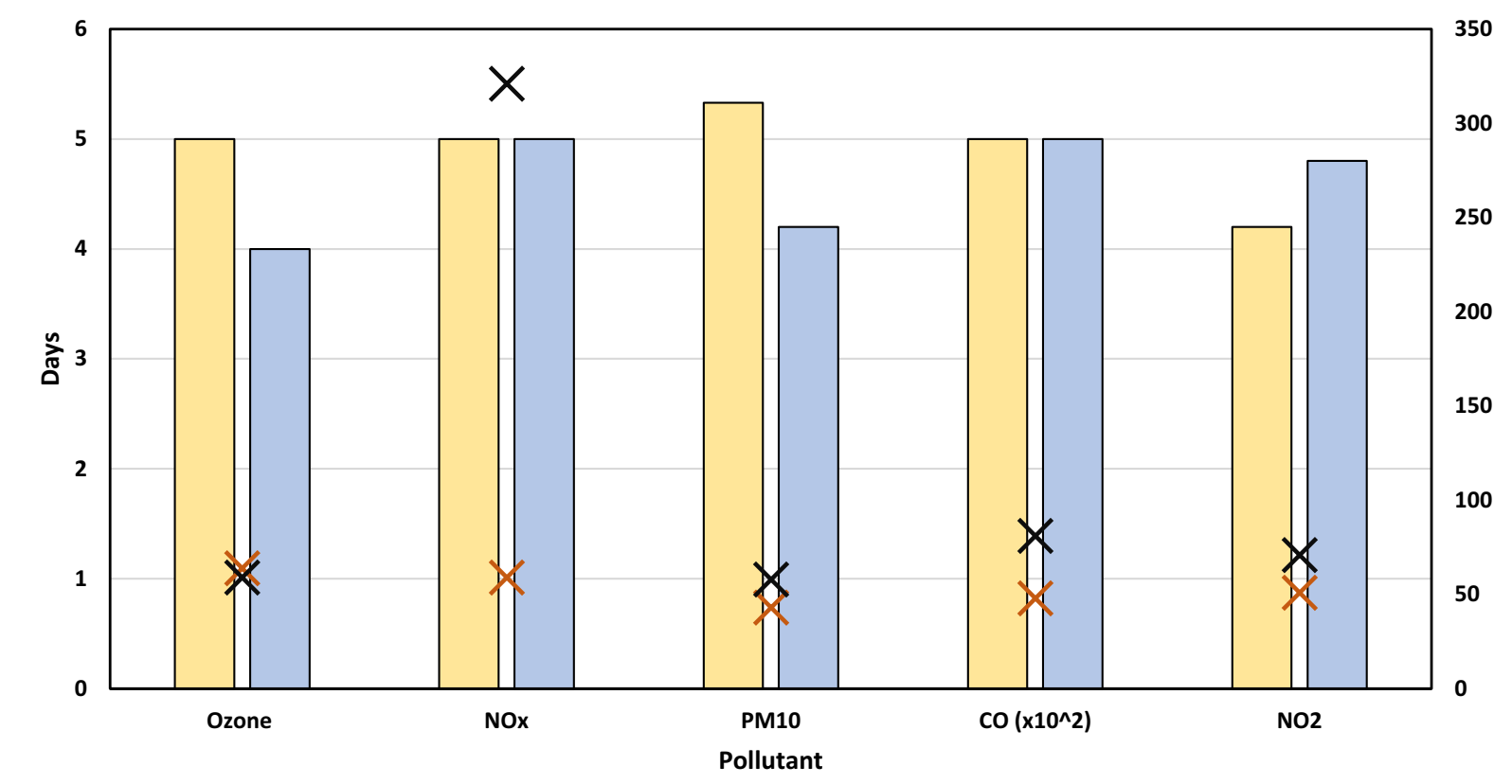

50

$\square$ Summer Duration $\quad \square$ Winter Duration

XSummer Concentration

XWinter Concentration

Fig. 11 The arithmetic mean length in days of a severe pollution episode in summer and winter (bars), overlaid by their average concentrations (crosses)

the weather in Birmingham tends either to be mild and wet or cold and dry.

In summer, PC $1(39.2 \%)$ is a hygrometric pressure component, with humid and cyclonic conditions occurring on days with high positive scores. This mode of variability was also identified by McGregor and Bamzelis (1995). PC 2 (18\%) is a thermal meridional wind component; hot, southerly winds occur on days with high positive scores. Kalkstein and Corrigan (1986) identified thermal variation as the most significant mode of variation (i.e. PC 1) in Wilmington, Delaware. PC $3(15.7 \%)$ is a zonal wind component, with strong westerlies propagating Atlantic low pressure systems over Britain on days with high positive PC 3 scores. Significantly, McGregor and Bamzelis (1995) found Birmingham's PC 3 to be a zonal flow component.

\subsection{Air mass types}

Cluster Analysis (CA) identified six air mass types in winter and summer. McGregor et al. (1999) also found six winter air mass types in Birmingham, including the Binary Mid-latitude Anticyclonic Maritime-Sub-polar Cyclonic Maritime (AM-SCM), that appeared as winter air mass type four in this study. McGregor's (1999) six winter Birmingham air mass types were similar to those in this study. In winter (summer), five (four) of the six air mass types were maritime, which reflects the dominance of westerly winds in Britain's wind climatology.

\subsection{Pollutant variability with air mass type}

The ANOVA (Table 6) and post-hoc Tukey tests (Fig. 5) showed statistically significant pollutant concentration differences between winter air mass types. These differences occur disproportionately when Returning Polar Maritime (air mass type six), which has the lowest average pollutant concentrations, is compared to the other five air mass types. The Returning Polar Maritime air mass is characterised by low pressure and strong upper-level westerlies that encourage the dispersion of pollutants. Anticyclonic winter air mass types (AT), such as AT 4 AM-SCM, are conducive to pollutant stagnation. The northerly and easterly flows that occur in these air mass types are cold and stable. This accentuates ground-based temperature inversions, which suppress turbulence and the boundary layer mixing height (McGregor 1999). The calm conditions suppress vertical pollutant diffusion in winter. Crucially, McGregor et al. (1999) identified identical cold, anticyclonic air mass types in Birmingham to those in this study (AT 3 and AT4); and found they produced the greatest conditional probabilities of inducing the highest respiratory admissions index class when PM10 was simultaneously the highest. 

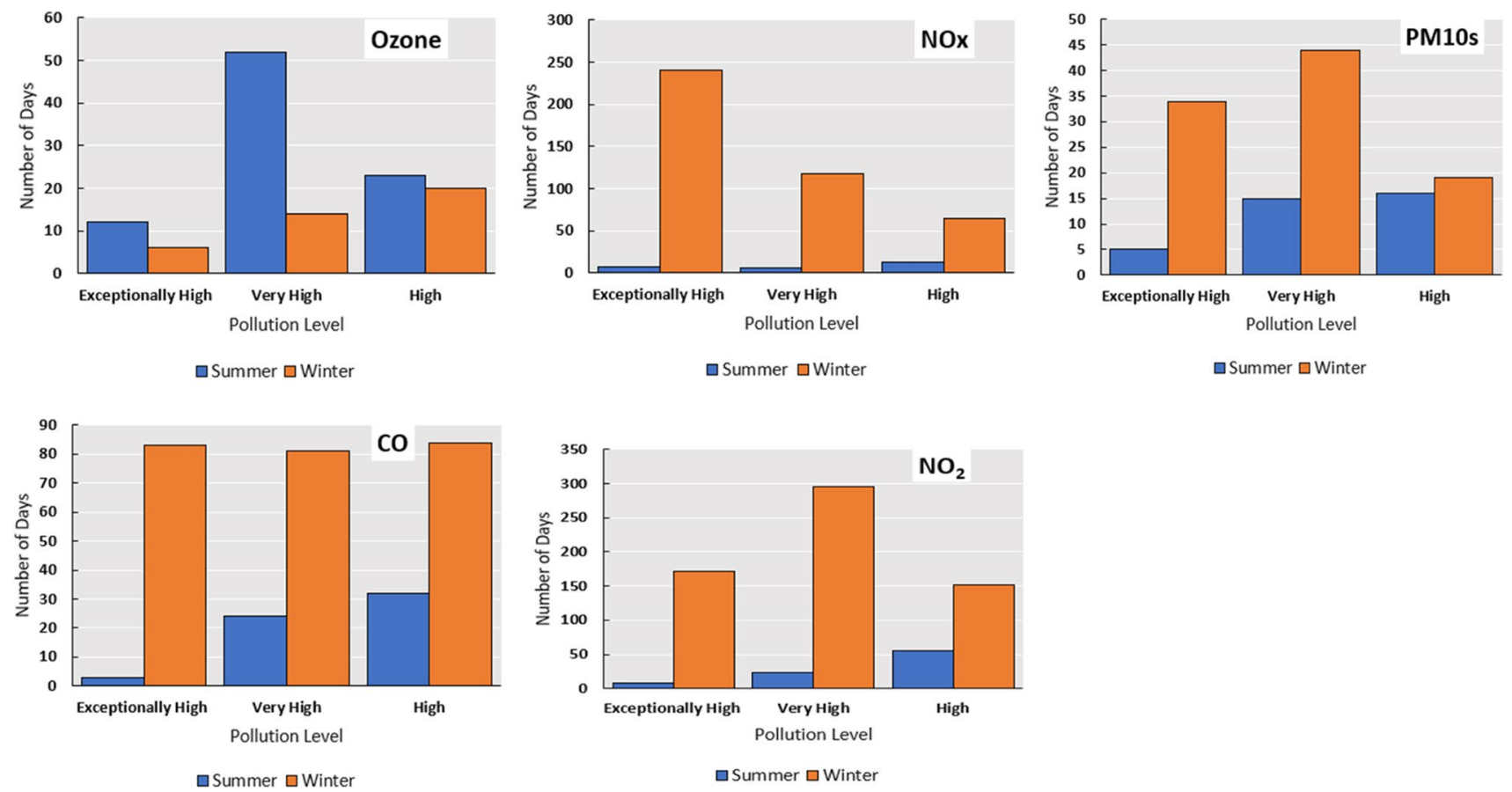

Fig. 12 The number of days ( $y$ axis) that pollutant concentrations are exceptionally high, very high and high in summer and winter over the 15-year study period (2000 to 2015)

The ANOVA (Table 6) and post-hoc Tukey test (Fig. 6) results showed statistically significant pollutant concentration differences between summer air mass types. These differences disproportionately occur when Tropical Continental (AT 5), which has the highest concentration for three of the five pollutants, is compared to the other five air mass types. Tropical continental air masses are typically characterised by anticyclonic conditions that are conducive to low cloud cover, low wind speeds and atmospheric stability (Comrie, 1992). This limits the ventilation and dispersion of pollutants because advective mixing is suppressed and a strong atmospheric subsidence exists, resulting in anomalously high pollutant concentrations. When McGregor and Bamzelis (1995) derived their air mass types across all seasons for Birmingham, they found that $\mathrm{NO}_{2}$ concentrations under anticyclonic continental air masses were more than double that of a cyclonic westerly air mass type. In our study, mean $\mathrm{NO}_{\mathrm{x}}$ in Birmingham under the Tropical Continental air mass is almost double that of the Polar Maritime air mass type. The passage of the Tropical Continental air mass over Europe's industrial and urban centres is also conducive to high pollutant concentrations. Kalisa et al. (2018) found that $\mathrm{O}_{3}$, PM10 and $\mathrm{NO}_{2}$ increased markedly during heatwaves in Birmingham, which sometimes occur under the Tropical Continental air mass.

Our study indicated a significant difference in $\mathrm{O}_{3}$ concentrations between air mass types in both winter and summer. Winter Returning Polar Maritime (AT 6) and summer
Tropical Continental (AT 5) possessed the highest mean

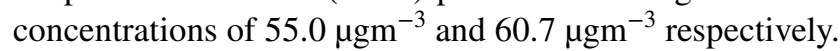
These air mass types are characterised by low cloud cover. The resulting increase in radiation - more apparent in summer AT 5-causes $\mathrm{NO}_{2}$ to dissociate $\mathrm{NO}_{2}$ into $\mathrm{NO}$ and $\mathrm{O}$, which are the precursors of $\mathrm{O}_{3}$ formation via photolysis (McGregor and Bamzelis 1995). This link can be corroborated by the low $\mathrm{NO}_{2}$ concentrations that occur in air mass types associated with less cloud cover; e.g. winter AT 6

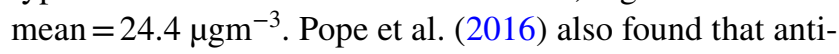
cyclonic conditions and easterly flows led to above average summer $\mathrm{O}_{3}$ concentrations across Britain.

\subsection{Distribution of air mass types on the most polluted days}

In winter, Polar Continental (AT 3) and AM-SCM (AT 4) occurred more frequently than expected on the most polluted days. These air masses are characterised by cold, anticyclonic conditions, with air originating from the north and the east. These conditions are conducive to temperature inversions and therefore pollutant stagnation. This supports the findings of McGregor et al. (1999), which found that the sub-polar continental anticyclonic air mass type (similar to this study's Polar Continental) was disproportionately represented on the most polluted days in Birmingham. Conversely, Unstable Tropical Maritime (AT 2) is under-represented on days with high concentrations. 
During the summer, Stable Anticyclonic Tropical (AT 3) and Tropical Continental (AT 5) disproportionately occur on the most polluted days for all pollutants. These air mass types are characterised by warm to hot temperatures and light wind conditions. These synoptic flow types sometimes lead to Saharan dust being transported to Britain. A neutral to stable atmosphere suppresses vertical motion by impeding buoyancy and turbulent eddy motions. This leads to poor ventilation and reduced dispersion of pollutants (Cheng and Lam 2000). Baker (2010) related pollutant concentrations in Birmingham to the air's trajectory during the previous four days. He found that the highest concentrations of primary pollutants were associated with slow moving easterly air masses from Continental Europe, whilst the lowest concentrations were associated with fast moving westerly and south-westerly air masses passing over the Atlantic Ocean. Similarly, elevated PM10 concentrations in Edinburgh were observed under anticyclonic, southerly and south-easterly weather types (Buchanan et al. 2002).

\subsection{Severe pollution episodes}

In winter, anticyclonic air masses Polar Continental (AT 3) and AM-SCM (AT 4) were found to be most favourable to severe winter pollution episodes. Crucially, McGregor et al. (1999) found that these two air mass types tend to occur together in a sequence during the winters of 1988-1994 in Birmingham. Elevated respiratory response to pollutants can occur due to the changing nature of persistent winter anticyclonic weather from fine, cold and dry (AM-SCM) to overcast, cool and humid conditions (Polar Continental) advected from the north-east. Episodes of the AM-SCM air mass type creates a 'sensitising mechanism' by which cold, stable conditions occur in conjunction with elevated pollutant concentrations to prime the population's respiratory response, which is activated by the persistence of cool, moist flows of the Polar Continental air mass. While surface temperature inversions are a primary contributor to severe pollution days, inversions of nocturnal origin typically last only 6 to $12 \mathrm{~h}$; and are thus rarely a primary causal mechanism of winter severe pollution episodes (Kassomenos et al. 2007). High concentrations are unlikely to persist under the Unstable Tropical Maritime (AT 2) and Returning Polar Maritime (AT 6) air mass types, which proves that the advection of strong Atlantic westerlies disperses pollutants.

During the summer, Tropical Continental (AT 5) and Mild Stable Polar Continental (AT 4) were most susceptible to severe pollution episodes. These air mass types are often accompanied by an upper-level ridge and subsidence in the atmosphere. Severe summer $\mathrm{O}_{3}$ pollution episodes only occurred under the Tropical Continental air mass (AT 5) type, a function of the high radiative input and calm conditions that characterise this airmass. Due to their cyclonic nature, Tropical Maritime (AT 1) and Transitional Polar Arctic (AT 2) produced few pollution episodes.

\subsection{Cross-seasonal comparison of pollution episode severity}

For all pollutants, the average duration of pollution episodes varies little between winter and summer. This similarity is likely due to distinctive air mass types in both seasons that are conducive to stability, namely Tropical Continental (AT 5) in summer, and Polar Continental (AT 3) and AM-SCM (AT 4) in winter. As expected, severe $\mathrm{O}_{3}$ episodes last on average one day longer in summer because meteorological conditions favour increased photolysis, such as those experienced in the Tropical Continental air mass type.

\subsection{Cross-seasonal comparison of pollution extreme values}

With the exception of $\mathrm{O}_{3}$, all pollutants (and especially $\mathrm{NO}_{\mathrm{x}}$ ) have a significantly greater number of extreme pollution days in winter than in summer. This seasonal difference is partly explained by winter temperature inversions, which create enhanced atmospheric stability. In Birmingham, this occurs mainly through surface radiation inversions, in which the Earth's surface rapidly cools on clear and calm nights, creating a warmer boundary layer above the cooled surface. This suppresses atmospheric turbulence and mixing. It is significant that the two winter air mass types with the coolest temperatures and some of the lowest wind speeds (AM-SCM AT 4 and Extreme Arctic Maritime AT 5) have on average the greatest pollutant concentrations (except $\mathrm{O}_{3}$ ) of all 12 air mass types across winter and summer. Increased levels of $\mathrm{NO}_{2}$ and $\mathrm{CO}$ in winter months can also be attributed to their significantly reduced influence on photochemical reactions occurring in photolysis for $\mathrm{O}_{3}$ formation (Cichowicz et al. 2017). The meteorological contribution to significantly higher $\mathrm{NO}_{\mathrm{x}}$ concentrations in winter may be of secondary importance. A three-fold increase in winter cloud cover would be expected to decrease photolysis such that the reduced reaction of $\mathrm{NO}_{2}$ and sunlight should directly decrease $\mathrm{NO}_{\mathrm{x}}$ production. Thus, the possible anthropogenic contributions to seasonal differences will now be explored.

Hamilton et al. (2009) indicate that the anthropogenic heat flux, the energy emitted from human activity in urban environments, almost doubles from summer to winter. During the winter, the use of electricity, central heating and gasoline (mainly vehicle engines) increases greatly because of the colder conditions. Gavin (2014) reported that electricity demand increased by $23 \%$ during the winter in the West Midlands. Moreover, fewer people walk and cycle in the winter and instead take to pollutant-producing vehicle transport (Yang et al. 2011). It follows that increased winter 
anthropogenic heat emissions in cities result in CO, PM10 and especially $\mathrm{NO}_{\mathrm{x}}$ being released at a greater rate.

Pollutant concentrations found in this paper often exceed EC (2019) and WHO (2005) guidelines (see Section 2), especially in winter. This has significant implications for human health, given that those with respiratory diseases are at considerable risk during elevated concentrations of pollutants such as $\mathrm{NO}_{2}$ and PM10. McGregor et al. (1999) demonstrated the relationship between respiratory-induced hospital admissions in Birmingham and air mass types. Their study revealed that PM10 concentrations exceeded the WHO's 50 $\mu \mathrm{gm}^{-3}$ threshold $22 \%$ of the time during anticyclonic Polar Continental air mass types, which correlated significantly with higher respiratory admissions. Pollutant concentrations also play a role in determining heart disease mortality rates in Birmingham (McGregor 1999).

The main limitation of our paper is that it has analysed weather-pollution relationships at the daily timescale using the mean value of 24 hourly observations. In mobile situations, it is possible for multiple air mass types to occur on the same day. There was also an imperfection in the method used to calculate the wind components $\mathrm{U}$ and $\mathrm{V}$, which misrepresented some days' wind flow. For example, on the 23rd January, 2001, the wind direction was averaged as an easterly despite a 5-h $19 \mathrm{~mm}$ rainfall event occurring under a strong westerly flow. Thus, the statistical analyses were unable to identify this rainfall event as being a westerlyinduced phenomenon. However, a complete reversal in the wind direction (e.g. westerly to easterly; southerly to northerly) rarely occurs at the sub-daily timescale, which means that the above problem does not occur frequently. Some researchers (e.g. Cheng and Lam 2000) overcame the problem of intra-diurnal variability by using six hourly averages. Whilst our paper uses 15 years of data, it is acknowledged that using linear regression to correct the values at Birmingham Centre to those at Tyburn between 2000-4 might have stripped out potentially extreme values at the latter site over this time period. This is because the regression line's position is constrained by having to pass through the bi-variate mean centre.

Future research should replicate the principal component and cluster analyses presented in this paper in spring and autumn, and at the sub-daily timescale (e.g. six or 12-hourly means). Diurnal variations in pollutant concentrations would firstly have to be removed (e.g. calculate hourly standardised scores) before these sub-daily air mass types could be related to air quality data. Another avenue of further research could compare pollutant-air mass type relationships to health indicators, such as respiratory admissions or ischaemic heart disease data. Multi-variate analysis of variance could be used to test statistically the tripartite relationship between air mass types, pollution and concurrent health impacts rather than simply inferring it. Such research could be an invaluable device for authorities to forecast scenarios of concern to public health. This could be communicated to the public by means of a synoptic index. This paper has only used surface meteorological variables. Variables that capture vertical atmospheric stability (e.g. vertical temperature gradient) could be added to the analysis.

\section{Conclusion}

This study's primary aim was to examine whether a relationship exists between pollution and weather types, and whether this association varies seasonally. Principal component and cluster analyses were used to derive the air mass types, which were then related to pollutant concentrations. High concentrations are associated with anticyclonic types. In summer, such air mass types are characterised by low wind speeds, which leads to decreased advective mixing. During the winter, similar meteorological conditions are often combined with nocturnal radiative cooling. This creates a temperature inversion near the ground, which also suppresses the vertical dispersion of pollutants.

The Tropical (Polar) Continental air mass type was most conducive to exceptionally high and very high concentrations in summer (winter). Turbulence is suppressed and the atmosphere is stable in these air mass types. In winter, a sequence of Polar Continental (cool and humid) and Binary Mid-latitude Anticyclonic Maritime-Sub-polar Cyclonic Maritime (cold and dry) induced severe pollution episodes in all pollutants, which can elevate the respiratory response in the general population by creating a sensitising mechanism.

The mean duration of a severe pollution episode duration varied little between winter and summer due to the strong presence of anticyclonic air mass types in both seasons. Naturally, increased photolysis results in severe $\mathrm{O}_{3}$ episodes lasting $20 \%$ longer in summer than in winter. With the exception of $\mathrm{O}_{3}$, high pollutant extremes were more common in winter. This was due to more favourable meteorological conditions and increased anthropogenic emissions during the cold season. Epidemiological evidence indicates that such high concentrations (e.g. one quarter of winter days exceeded the WHO and EC threshold of $50 \mu \mathrm{gm}^{-3}$ for $\mathrm{NO}_{2}$ ) can exasperate heart and respiratory diseases in Birmingham.

This study has clearly shown that an objective, synoptic airmass approach can be used to understand the macroscale controls of different weather types on pollutant concentrations. Given that pollutant guidelines were often breached during the study period, a concerted effort in the future to understand the complex relationship between meteorological conditions and anthropogenic-pollution relationship may have crucial epidemiological and societal implications. 
Author contribution The first author obtained the data and performed all of the analyses. The second author edited the first author's work.

Funding Self-funded.

Data availability Data sets used are freely available.

Code availability Not applicable.

\section{Declarations}

Ethics approval The submitted work is original and has not been published elsewhere in any form or language.

Consent to participate This paper is based on the analysis of secondary data sets. Hence, the only participants are the two authors.

Consent for publication No persons were interviewed or questioned.

Conflict of interest The authors declare no competing interests.

Open Access This article is licensed under a Creative Commons Attribution 4.0 International License, which permits use, sharing, adaptation, distribution and reproduction in any medium or format, as long as you give appropriate credit to the original author(s) and the source, provide a link to the Creative Commons licence, and indicate if changes were made. The images or other third party material in this article are included in the article's Creative Commons licence, unless indicated otherwise in a credit line to the material. If material is not included in the article's Creative Commons licence and your intended use is not permitted by statutory regulation or exceeds the permitted use, you will need to obtain permission directly from the copyright holder. To view a copy of this licence, visit http://creativecommons.org/licenses/by/4.0/.

\section{References}

Abbott J, Conolly C, Cooke S, Passant N, Stewart R, Wagner A (2012) Assessment of the effectiveness of measures under the Clean Air Act 1993. Department for Environment, Food and Rural Affairs, British Government Publication (106pp)

Baker J (2010) A cluster analysis of long range air transport pathways and associated pollutant concentrations within the UK. Atmos Environ 44:563-571. https://doi.org/10.1016/j.atmosenv.2009. 10.030

Bloss W (2018) What should we do about air pollution in Birmingham? The HuffPost. https://www.huffingtonpost.co.uk/entry/airpollution-birmingham_uk_5b3dd2ffe4b05127ccef1f59?gucco unter $=1 \&$ guce_referrer_us $=$ aHR0cHM6Ly93d 3cuZ29vZ2x1L mNvbS8\&guce_referrer_cs=fJD_O91XMxWGFYUQ69SHNA. Accessed 2 Jan 2019

Buchanan CM, Beverland IJ, Heal MR (2002) The influence of weather-type and long-range transport on airborne particle concentrations in Edinburgh, UK. Atmos Environ 36:5343-5354. https://doi.org/10.1016/S1352-2310(02)00579-4

Chelani $\mathrm{AB}$ (2013) Study of extreme $\mathrm{CO}, \mathrm{NO}_{2}$ and $\mathrm{O}_{3}$ concentrations at a traffic site in Delhi: statistical persistence analysis and source identification. Aerosol Air Qual Res 13:377-384. https://doi.org/ 10.4209/aaqr.2011.10.0163

Chen Z, Barros CP, Gil-Alana L (2016) The persistence of air pollution in four mega-cities of China. Habitat Int 56:103-108. https://doi. org/10.1016/j.habitatint.2016.05.004
Cheng S, Lam KC (2000) Synoptic typing and its application to the assessment of climatic impact on concentrations of sulfur dioxide and nitrogen oxides in Hong Kong. Atmos Environ 34:585-594. https://doi.org/10.1016/S1352-2310(99)00194-6

Cichowicz R, Wielgosinski G, Fetter W (2017) Dispersion of atmospheric air pollution in summer and winter season. Environ Monit Assess 189, Article Number 605. https://doi.org/10.1007/ s10661-017-6319-2

Comrie AC (1992) An enhanced synoptic climatology of ozone using a sequencing technique. Phys Geogr 13:53-65. https://doi.org/10. 1080/02723646.1992.10642444

DEFRA (2018) Air Pollution in the UK 2017. Department for Environment, Food and Rural Affairs, British Government Publication 132pp)

DEFRA and DfT (2017) Improving air quality in the UK: tackling nitrogen dioxide in our towns and cities. Department for Environment, Food and Rural Affairs and the Department for Transport, British Government Publication, 86pp

European Commission (2019) Air Quality Standards. https://ec. europa.eu/environment/air/quality/standards.htm. Accessed 5 Mar 2021

Gavin C (2014) Seasonal variations in electricity demand: special feature for electricity statistics. GovUK, 4pp. https://assets.publi shing.service.gov.uk/government/uploads/system/uploads/attac hment_data/file/295225/Seasonal_variations_in_electricity_ demand.pdf. Accessed 5 Mar 2019

Gower JC, Banfield CF (1975) Goodness-of-fit criteria for hierarchical classification and their empirical distributions. The Proceedings of the International Biometric Conference, Raleigh, N.C. Biometric Society, pp 347-62

Hamilton IG, Davies M, Steadman P, Stone A, Ridley I, Evans S (2009) The significance of the anthropogenic heat emissions of London's buildings: a comparison against captured shortwave solar radiation. Build Environ 44:807-817. https://doi.org/10. 1016/j.buildenv.2008.05.24

Hatton T (2017) Air pollution in Victorian-era Britain - its effects on health now revealed. The Conversation. https://theconversation. com/air-pollution-in-victorian-era-britain-its-effects-on-healthnow-revealed-87208. Accessed 29 Dec 2018

Hayer SS (2021) The impact of meteorological factors on air pollution at Birmingham Airport. BSc Geography Dissertation, University of Birmingham, UK. 91pp

Kaiser HF (1960) The application of electronic computers to factor analysis. Educ Psychol Meas 20:141-151

Kalisa E, Fadlallah S, Amani M, Nahayo L, Habiyaremye G (2018) Temperature and air pollution relationship during heatwaves in Birmingham, UK. Sustain Cities Soc 43:111-121. https://doi. org/10.1016/j.scs.2018.08.033

Kalkstein LS, Corrigan P (1986) A synoptic climatological approach for geographical analysis: assessment of sulfur-dioxide concentrations. Ann Am Assoc Geogr 76:381-395. https://doi.org/10. 1111/j.1467-8306.1986.tb00126.x

Kalkstein LS, Tan GR, Skindlov JA (1987) An evaluation of three clustering procedures for use in synoptic climatological classification. J Appl Meteorol 26:717-730. https://doi.org/10.1175/ 1520-0450(1987)026\%3c0717:AEOTCP\%3e2.0.CO;2

Kassomenos PA, Gryparis A, Katsouyanni K (2007) On the association between daily mortality and air mass types in Athens, Greece during winter and summer. Int J Biometeorol 51:315322. https://doi.org/10.1007/s00484-006-0062-7

Liang J (2021) The impact of weather variables on air pollutants in Birmingham, UK. BSc Environmental Science Dissertation, University of Birmingham, UK. 87pp

Lonati G, Cernuschi S, Giugliano M (2011) The duration of PM10 concentration in a large metropolitan area. Atmos Environ 45:137-146. https://doi.org/10.1016/j.atmosenv.2010.09.033 
McGregor GR (1999) Winter ischaemic heart disease deaths in Birmingham, United Kingdom: a synoptic climatological analysis. Clim Res 13:17-31. https://doi.org/10.3354/cr013017

McGregor GR, Bamzelis D (1995) Synoptic typing and its application to the investigation of weather air-pollution relationships, Birmingham, United Kingdom. Theor Appl Climatol 51:223236. https://doi.org/10.1007/BF00867281

McGregor GR, Walters S, Wordley J (1999) Daily hospital respiratory admissions and winter air mass types, Birmingham, UK. Int J Biometeorol 43:21-30. https://doi.org/10.1007/s004840050 112

Pope RJ, Butt EW, Chipperfield MP, Doherty RM, Fenech S, Schmidt A, Arnold SR, Savage NH (2016) The impact of synoptic weather on UK surface ozone and implications for premature mortality. Environ Res Lett 11:124004. https://doi.org/10.1088/1748-9326/ $11 / 12 / 124004$

Shahgedanova M, Burt TP, Davies TD (1998) Synoptic Climatology of Air Pollution in Moscow. Theor Appl Climatol 61:85-102. https:// doi.org/10.1007/s007040050054

Tselepidaki IG, Asimakoupoulos DN, Katsouyanni K, Moustris C, Touloumi G, Pantazopoulou A (1995) The use of complex thermohygrometric index in predicting adverse health effects in Athens. Int J Biometeorol 38:194-198. https://doi.org/10.1007/ BF01245388
Varotsos CA, Efstathiou MN, Kondratyev KY (2003) Long-term variation in surface ozone and its Precursors in Athens, Greece - A forecasting tool. Environ Sci Pollut 10:19-23

World Health Organisation (2005) WHO Air quality guidelines for particulate matter, ozone, nitrogen dioxide and sulfur dioxide. World Health Organisation, 22pp

Xie WX, Li G, Zhao D, Xie XQ, Wei ZH, Wang W, Wang M, Li GX, Liu WR, Sun JY, Jia ZR, Zhang Q, Liu J (2015) The Relationship between fine particulate air pollution and ischemic heart disease morbidity and mortality. Heart 101:255-264. https://doi.org/10. 1136/heartjnl-2014-306165

Yang Y, Roux AVD, Bingham CR (2011) Variability and seasonality of active transportation in USA: evidence from the 2001 NHTS. Int J Behav Nutr Phys Act 8, Article Number 96. https://doi.org/ $10.1186 / 1479-5868-8-96$

Yarnal B (1993) Synoptic Climatology in Environmental Analysis: a primer. Belhaven Press, London, p 195

Publisher's note Springer Nature remains neutral with regard to jurisdictional claims in published maps and institutional affiliations. 